\title{
Technical and economic feasibility of centralized facilities for solar hydrogen production via
}

Cite this: Energy Environ. Sci., 2013, 6, 1983

\author{
Blaise A. Pinaud, ${ }^{a}$ Jesse D. Benck, ${ }^{a}$ Linsey C. Seitz, ${ }^{a}$ Arnold J. Forman, ${ }^{a}$ Zhebo Chen, ${ }^{a}$ \\ Todd G. Deutsch, ${ }^{\mathrm{b}}$ Brian D. James, ${ }^{\mathrm{c}}$ Kevin N. Baum, ${ }^{\mathrm{c}}$ George N. Baum, ${ }^{\mathrm{c}}$ Shane Ardo, ${ }^{d}$ \\ Heli Wang, ${ }^{\text {b }}$ Eric Millere and Thomas F. Jaramillo*a
}

Photoelectrochemical water splitting is a promising route for the renewable production of hydrogen fuel. This work presents the results of a technical and economic feasibility analysis conducted for four hypothetical, centralized, large-scale hydrogen production plants based on this technology. The four reactor types considered were a single bed particle suspension system, a dual bed particle suspension system, a fixed panel array, and a tracking concentrator array. The current performance of semiconductor absorbers and electrocatalysts were considered to compute reasonable solar-tohydrogen conversion efficiencies for each of the four systems. The U.S. Department of Energy H2A model was employed to calculate the levelized cost of hydrogen output at the plant gate at 300 psi for a 10 tonne per day production scale. All capital expenditures and operating costs for the reactors and auxiliaries (compressors, control systems, etc.) were considered. The final cost varied from $\$ 1.60-\$ 10.40$ per $\mathrm{kg} \mathrm{H}_{2}$ with the particle bed systems having lower costs than the panel-based systems. However, safety concerns due to the cogeneration of $\mathrm{O}_{2}$ and $\mathrm{H}_{2}$ in a single bed system and long molecular transport lengths in the dual bed system lead to greater uncertainty in their operation. A sensitivity analysis revealed that improvement in the solar-to-hydrogen efficiency of the panel-based systems could substantially drive down their costs. A key finding is that the production costs are consistent with the Department of Energy's targeted threshold cost of $\$ 2.00-\$ 4.00$ per $\mathrm{kg} \mathrm{H}_{2}$ for dispensed hydrogen, demonstrating that photoelectrochemical water splitting could be a viable route for hydrogen production in the future if material performance targets can be met.
Received 10th March 2013

Accepted 20th May 2013

DOI: $10.1039 / \mathrm{c} 3 \mathrm{ee} 40831 \mathrm{k}$

www.rsc.org/ees

\section{Broader context}

As global energy consumption continues to rise, it is imperative that we develop renewable alternatives to the fossil fuel energy sources that currently power our civilization, curb $\mathrm{CO}_{2}$ emissions, and secure a permanent energy supply for the future. Although the solutions to these global challenges are likely to consist of many different energy storage and conversion technologies, sustainably produced chemical fuels will likely play an important role due to their high energy density. Hydrogen gas is an especially promising energy carrier, but current hydrogen production processes such as steam methane reforming are unsustainable. Photoelectrochemical (PEC) water splitting is an alternative process that enables sustainable hydrogen production from water using the energy from sunlight. PEC water splitting has been demonstrated on the laboratory scale, but it has never been implemented on a large scale relevant to the global energy demand, so the prospects for scaling up this process have remained controversial. The present paper addresses the technical and economic feasibility of plants producing hydrogen via PEC water splitting. We establish practical operating efficiencies for PEC reactors, detail four potential reactor and centralized plant designs, and discuss the projected cost of the hydrogen produced using each design. Through this analysis, we establish that PEC water splitting has the potential to be technically and economically viable. To help guide continuing research in this field, we identify key challenges that must be overcome to drive down the cost of large-scale hydrogen production by PEC water splitting.

${ }^{a}$ Department of Chemical Engineering, Stanford University, 381 North-South Axis, Stanford, 94305, USA. E-mail: jaramillo@stanford.edu; Fax: +1-650-725-7294; Tel: $+1-650-498-6879$

${ }^{b}$ National Renewable Energy Laboratory, 15013 Denver West Parkway, Golden, 80401, USA. E-mail: Todd.Deutsch@nrel.gov; Heli.Wang@nrel.gov; Fax: +1-303275-3840; Tel: +1-303-275-3727

'Strategic Analysis Inc., 4075 Wilson Boulevard, Suite 200, Arlington, 22203, USA.

E-mail: BJames@sainc.com; Fax:+1-703-778-7114; Tel: +1-703-527-5410
${ }^{d}$ Department of Chemistry, California Institute of Technology, 1200 E. California Blvd, Pasadena, USA. E-mail: sardo@caltech.edu; Fax: +1-626-395-8867; Tel: +1626-395-3964

${ }^{e}$ US Department of Energy, 1000 Independence Avenue SW, Washington, 20585, USA. E-mail: Eric.Miller@ee.doe.gov; Fax: +1-202-586-2373; Tel: +1-202-287-5829 


\section{Introduction}

Intensive research and development efforts over the past few decades on nonfossil fuel-based energy solutions have led to a steady increase in incorporation of these technologies into the electrical grid. Examples include electricity generation by wind turbines and solar photovoltaics, technologies that are seeing increased market penetration. The issue of intermittency, however, will hinder large-scale deployment of a number of these carbon-free energy sources by creating problems in maintaining overall grid stability. The synthesis of chemical fuels by using intermittent renewable energy is one pathway to circumvent this instability; chemical fuels can be generated while the wind is blowing or the sun is shining and can be consumed to meet changing power demand. Furthermore, the energy density of chemical fuels far exceeds that of capacitors and batteries. For renewable chemical fuels to make up a significant fraction of the world's ever-increasing energy needs, production must match the sizeable global demand. It is important to ask whether renewable fuel-based systems currently being developed in the laboratory could potentially be viable in the energy market and deployable on such a large scale. The goal of the work presented herein is to evaluate the economic feasibility of solar hydrogen production, a method extensively researched for renewable fuel generation. This task is accomplished by assessing achievable system efficiencies via calculations and a survey of existing bench-scale materials, then computing the cost of hydrogen output from several conceptual large-scale reactor designs based on reasonable commercial and economic assumptions.

Molecular hydrogen is one of the many chemical fuels being explored. As a commodity, hydrogen is already produced on a large scale (50 million tonnes per year worldwide ${ }^{1}$ ), used mostly for petroleum refining as well as the synthesis of ammonia for fertilizer. The majority (>95\%) of global hydrogen is currently produced from fossil fuels, primarily via steam methane reforming. ${ }^{1}$ Its envisioned use as a clean energy carrier on a large scale is hindered by the need for a cost-competitive, renewable production route and lack of storage and transportation infrastructure. A key advantage of renewable, solar hydrogen over fossil-based chemical fuels is that its use in fuel cells or combustion engines to power vehicles leads to no $\mathrm{CO}_{2}$ emissions. Many renewable hydrogen production technologies exist in various stages of development and these can be broken down into the following three main categories: thermal processes, electrolytic processes, and photolytic processes. The first category includes reforming of bio-derived fuels and thermal cycles with metal oxides $\left(\mathrm{M}_{x} \mathrm{O}_{y}\right.$ such as $\left.\mathrm{ZnO} / \mathrm{Zn}\right)$ or lower temperature cycles with $\mathrm{S}-\mathrm{I}$ or $\mathrm{Cu}-\mathrm{Cl}$ chemistries. ${ }^{2}$ The second consists of coupling a renewable electricity source, such as wind or solar, with an electrolyzer. ${ }^{3}$ Photolytic processes can be biological, making use of molecular complexes, hydrogenevolving enzymes, and natural organisms, ${ }^{4}$ or photoelectrochemical/photocatalytic involving molecular chromophores or semiconductor absorbers. This last technology is the focus of this work.
Photoelectrochemical (PEC) water splitting, a process in which solar energy is used to evolve $\mathrm{H}_{2}$ and $\mathrm{O}_{2}$ from water, is a promising technology because it offers a potentially affordable, carbon-free route to the synthesis of hydrogen. Another key benefit of this process is the high purity of the output hydrogen gas stream, an important requirement for its use in fuel cells. Since the seminal paper from Fujishima and Honda of 1972 describing the PEC water splitting process on a $\mathrm{TiO}_{2}$ photoelectrode, ${ }^{5}$ significant technical advances have resulted in functional bench-scale systems. PEC cells composed of III-V group semiconductors have demonstrated solar-to-hydrogen (STH) efficiencies as high as $\mathbf{1 2 . 4 \%}$ (ref. 6) and $18.3 \%$ (ref. 7) depending on the exact device configuration, while multijunction silicon PEC cells have yielded efficiencies in the range of $4.7 \%$ (ref. 8 ) to $7.8 \%$ (ref. 9) depending on the type of cocatalysts used. Each system faces technical scale-up challenges which range from improving durability to further increasing efficiency to lowering materials and manufacturing costs. Fundamentally, economics are the driving force in our energy landscape so there is one key question which all researchers in the field should be asking: if the technical barriers to implementation of photoelectrochemical water splitting on a large scale are overcome, can hydrogen be produced at a cost which is competitive with that of fossil fuels?

The United States Department of Energy (DOE) contracted Directed Technologies Inc. (DTI) (now Strategic Analysis Inc.) to carry out a detailed technoeconomic evaluation $\dagger$ of PEC hydrogen generation based on conceptual systems formulated by the DOE PEC Working Group. ${ }^{10}$ This team brings together university researchers, scientists from national laboratories, and industry leaders with experience in PEC water splitting systems. The major findings of their cost analysis are presented here in conjunction with an evaluation of the technical feasibility of the assumptions pertaining to material properties and system efficiencies. PEC hydrogen production has a very low technology readiness level (TRL 1-2) (11 $^{\mathbf{1}}$ but there is a need for an objective, unbiased technoeconomic analysis to determine where research dollars are best spent to lead to commercially viable solutions. This study emphasizes large-scale operations based on realistic material performance targets to calculate a cost for $\mathrm{H}_{2}$. Results of this study place the levelized cost of hydrogen for these systems between \$1.60-\$10.40 per $\mathrm{kg} \mathrm{H}_{2}$, indicating that commercial-scale PEC water splitting could be cost-competitive with fossil-based fuels.

\section{Photoelectrochemical water splitting}

\subsection{Basic operation principles}

The process of photoelectrochemical water splitting begins with the absorption of a solar photon in a semiconductor material to form an excited electron-hole pair. If the semiconductor is immersed in an aqueous electrolyte, band bending at the semiconductor/electrolyte interface provides a driving force for the separation of the photogenerated charge carriers. Band

$\dagger$ The full report issued by DTI can be found at http://www1.eere.energy.gov/ hydrogenandfuelcells/pdfs/pec_technoeconomic_analysis.pdf. 
bending can also be generated through the use of a $\mathrm{p} / \mathrm{n}$ junction or other solid state junction analogous to a solar cell. The excited holes must reach one surface to drive the oxygen evolution reaction (OER) while the electrons are consumed by the hydrogen evolution reaction (HER) at a separate electrode or surface. PEC hydrogen production systems can incorporate a single photoanode, a single photocathode, or multiple absorbers to make up a tandem device. Note that for a tandem system, the absorbers can be arranged optically in series or in parallel. In a single absorber system consisting of an n-type semiconductor photoanode, the OER occurs on the photoelectrode surface and electrons, the majority charge carriers, flow to the cathode. In a system consisting of a p-type semiconductor photocathode, the HER will occur on the photoelectrode surface and holes, the majority charge carriers, flow to the anode. In a tandem cell device, the overall water splitting process consists of the same reactions, but both the photoanode and photocathode absorb photons and create excited charge carriers. A tandem structure with two photoelectrodes is illustrated in Fig. 1 (the diagram is generic and not meant to reflect any particular device configuration). PEC water splitting is not limited to systems with panel electrodes. Suspensions of photocatalyst particles on which either one or both water splitting half-reactions occur have been studied. The merits of various device configurations are discussed later in the context of comparing the four potential system embodiments selected for analysis. Several comprehensive reviews ${ }^{\mathbf{1 2}}$ of the physics and chemistry, ${ }^{13}$ materials requirements ${ }^{14,15}$ and candidate semiconductors $^{16}$ have been published recently and the reader is referred to these for an in-depth review of the field. The focus herein is exclusively on the materials properties and costs which are relevant for the selection, sizing, and durability of a conceptual large-scale, centralized solar water splitting facility.

The key requirements for the semiconducting material(s) are a suitable band gap for light absorption, proper band edge

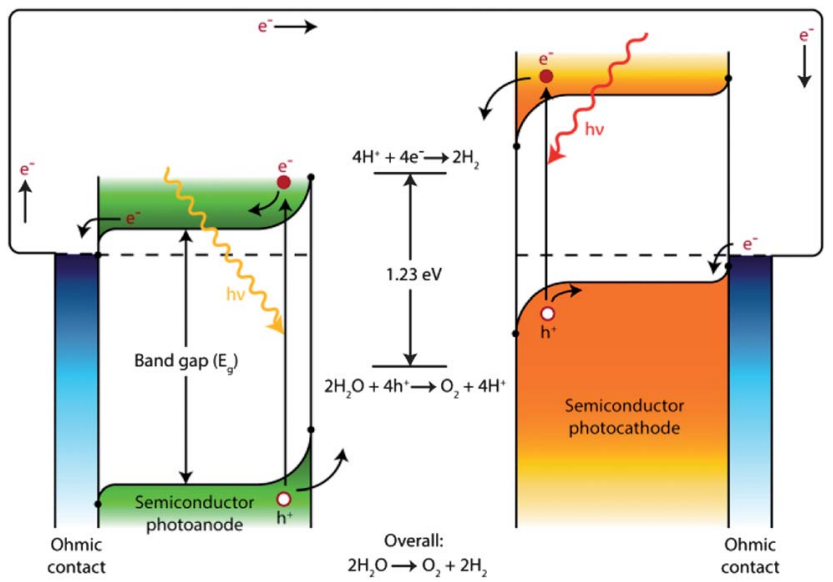

Fig. 1 Schematic band diagram showing the phenomena of photon absorption, band bending, charge separation, as well as hydrogen and oxygen evolution on semiconductor photoanode and photocathode surfaces. The external circuits could also be replaced by a redox mediator to shuttle charges between the two photoelectrodes. alignment for the redox reactions of interest, long term stability in an aqueous environment, as well as cost and material availability. The first material constraint of importance is the band gap. Thermodynamics dictate a minimum voltage requirement of $1.23 \mathrm{~V}$ to split water at standard temperature, pressure, and concentrations, thus necessitating at least a $1.23 \mathrm{eV}$ band gap semiconductor. In practice, however, entropic losses, reaction overpotentials, and other parasitic losses raise the overall band gap requirement. Simply put, the band gap must be large enough to provide the necessary photovoltage to split water but must be as small as possible to absorb the greatest portion of the solar spectrum. Solar photon flux utilization can be maximized by employing multiple smaller band gap absorber layers connected in series to yield a combined voltage large enough to split water at relevant reaction rates. This approach has proven successful in the photovoltaic industry ${ }^{17-19}$ as well as in laboratory PEC water splitting devices. ${ }^{6,7,9}$ The generation of the requisite photovoltage is a necessary but insufficient condition to split water. The energy levels at which the electrons and holes are injected to solution must exceed the electrochemical redox potentials for the HER and the OER, respectively. Thus, at the very least, the potential of the conduction band of the semiconductor at the semiconductor/liquid junction must be more negative than $0.0 \mathrm{~V} v s$. RHE while the valence band must be more positive than $1.23 \mathrm{~V}$ vs. RHE. Catalysis also plays an important role in PEC water splitting. Reducing the overpotential for each redox reaction lowers the total voltage required to obtain a rapid rate of water splitting. If the surface of the optimal absorber material is not inherently a good catalyst (which is oftentimes the case), it can be decorated with an HER or OER co-catalyst but care must be taken to ensure additional losses are not introduced at the semiconductor/catalyst interface due to shadowing or the formation of interfacial defect states. Charge transport within the absorber material and across the electrode/electrolyte interface must be fast to reduce recombination. Stability in an aqueous environment is essential for long term operation and plant durability. The electrode must not corrode or undergo any changes detrimental to performance either in the dark (nighttime conditions) or under illumination (daytime conditions). Lastly, the market cost and accessibility (e.g. earth abundance) of the constituent materials are key considerations if solar hydrogen from water splitting is to be viable on a large scale. ${ }^{20}$

\subsection{Calculation of practical system efficiencies}

The performance of PEC water splitting devices is best quantified by their solar-to-hydrogen efficiency, which is defined as the amount of chemical energy produced in the form of hydrogen divided by the solar energy input without the use of any external bias. There is also the additional requirement that the other coupled half-reaction must specifically be oxygen evolution in order to maintain a sustainable overall reaction in which sunlight and water are the only inputs. ${ }^{21} \mathrm{STH}$ efficiency is a metric by which device performances can be quantifiably compared on an equivalent basis, which is not possible with the inclusion of unsustainable inputs such as sacrificial reagents or 
with incomplete half-cell designs that drive only one of the two half-reactions (the HER or the OER).

In designing the conceptual water splitting systems described in this work, it was very important to select realistic efficiencies due to the impact on cost. Reasonable STH efficiencies for various PEC water splitting device configurations were calculated by taking into account total solar irradiance, entropic losses due to blackbody radiation and recombination, and kinetic overpotentials needed to drive the two half-reactions. As mentioned earlier, a thermodynamic minimum of 1.23 $\mathrm{V}$ is required to split water, but in practice the voltage required to drive this reaction increases due to these unavoidable losses. The calculations and corresponding assumptions included here both review and expand upon past work ${ }^{22-24}$ developed to determine upper limits of achievable efficiencies for the best available materials at this time. Other losses such as those due to nonideal band edge alignment and series resistances from the solution or wiring can further decrease the amount of usable voltage, but a full analysis of these effects is beyond the current scope of this work. One of the seminal derivations of solar conversion efficiencies was developed by Shockley and Queisser ${ }^{25}$ and later expanded upon by Ross, ${ }^{26}$ though the work was framed in the context of photovoltaic devices and thus did not aim to include losses unique to PEC systems such as the kinetic overpotentials required to drive electrochemical reactions. Weber and Dignam, ${ }^{22,23}$ Miller and Rocheleau, ${ }^{27}$ as well as Bolton et al. ${ }^{28}$ further elaborated on solar conversion efficiencies specifically addressing PEC systems. More recent work has focused on calculating efficiencies for tandem systems with various geometries. ${ }^{29}$ Prior to introducing the PEC-specific losses, it is instructive to consider the thermodynamic limits as an upper bound. Previous calculations have shown that a single absorber PEC system can reach $29 \%$ (ref. 30) to 31\% (ref. 24) while a tandem system with two absorbers could reach $40 \%$ (ref. 24 ) to $41 \% .{ }^{30}$ Taking into account multiple exciton generation or solar concentration raises these numbers further. ${ }^{24}$ Results presented in this paper are produced using the Air Mass 1.5 Global (AM 1.5 G) spectrum (ASTM G173-03) and a few updated assumptions, described briefly below to reasonably reflect the current state of technology for PEC materials. A more detailed description of the calculations will be made available elsewhere. $^{31}$

Eqn (1) is one definition for STH efficiency, using the product of voltage and short-circuit current to calculate the chemical power output of the PEC water splitting cell under standard-state conditions relative to the power input to the cell by 1 sun AM 1.5 G illumination, assuming 100\% Faradaic conversion of water to $\mathrm{H}_{2}$ and $\mathrm{O}_{2}$.

$$
\mathrm{STH}=\left[\frac{\left|j_{\mathrm{sc}}\left(\mathrm{mA} \mathrm{cm}^{-2}\right)\right| \times 1.23 \mathrm{~V}}{P_{\text {total }}\left(\mathrm{mW} \mathrm{cm}^{-2}\right)}\right]_{\mathrm{AM} 1.5 \mathrm{G}}
$$

The first step taken to calculate reasonably achievable STH efficiency values was deriving the maximum photocurrent under illumination for a given band gap by integrating the AM $1.5 \mathrm{G}$ spectrum. Here, there is no applied bias and ideal band edge alignment is assumed. Kinetic overpotentials as well as energy and entropic losses arising from material defects and nonradiative recombination were then calculated and subtracted to produce current-voltage relationships for each band gap from which the STH efficiency value was extracted. The maximum photocurrents were calculated by summing the absorbable photons over the solar spectrum for materials of varying band gaps assuming all photons with energy greater than the band gap are absorbed. The open-circuit voltages, used to estimate the useable photovoltage, were calculated for each band gap using the procedure outlined by $\operatorname{Ross}^{\mathbf{2 6}}$ and taking into account entropic losses modeled after single crystal silicon. Kinetic overpotentials were calculated for the range of possible currents drawn from the system assuming Butler-Volmer kinetics fitted to the hydrogen evolution and oxygen evolution activities of platinum and ruthenium oxide, respectively. ${ }^{32,33}$ Shunt losses were neglected in this treatment because their value is largely device dependent and not an intrinsic material property.

Results of these calculations are shown here for three different device configurations that reflect those employed in several reactor designs that will be presented later. The three configurations are a single photoabsorber system, a dual stacked photoabsorber system, and a dual side-by-side photoabsorber system. These configurations differ in the number and geometry of photoabsorber materials used which has a direct impact on the spectrum and number of photons absorbed in each material and thus the maximum possible STH efficiency. Fig. 2 shows the maximum practical theoretical limits for a single absorber system for which the maximum STH efficiency is $11.2 \%$ for a band gap of $2.26 \mathrm{eV}$. This calculation assumes that an area equal to that of the photoabsorber was available for each water splitting half-reaction; this restriction is not always necessary as a higher area electrode driving a reaction in the dark could be orthogonalized. Note that this value of $11.2 \%$ falls far short of the $31 \%$ thermodynamic limit, highlighting the large losses associated with reaction overpotentials and the need for better catalysts. Fig. 3 and 4 show the maximum practical STH efficiencies for dual stacked and side-by-side

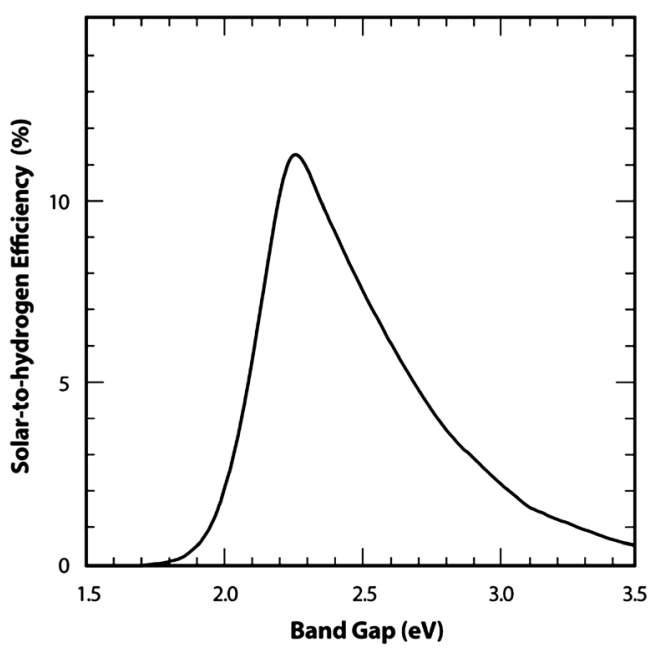

Fig. 2 Maximum theoretical solar-to-hydrogen efficiency for a single absorber material plotted as a function of the photoabsorber band gap. 


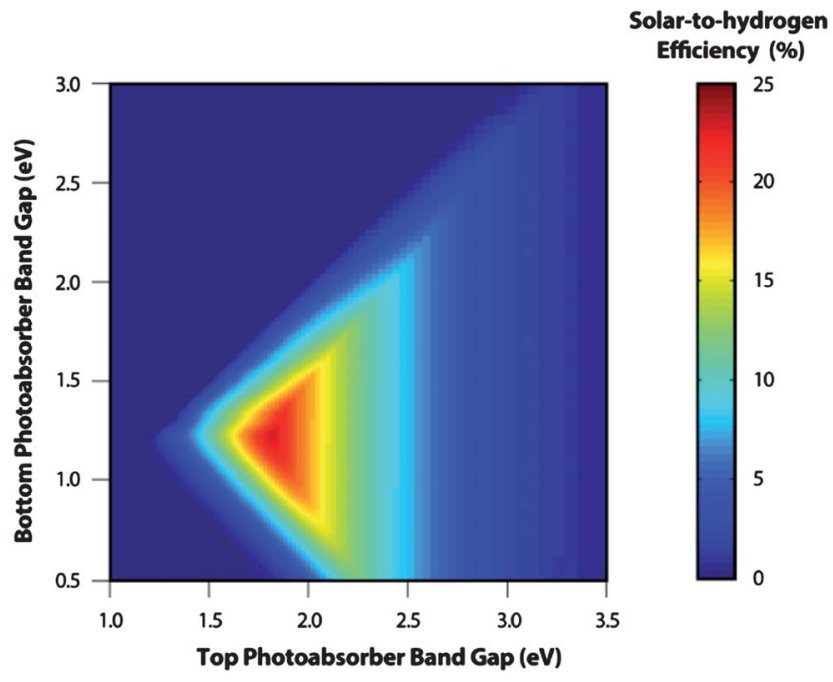

Fig. 3 Maximum theoretical solar-to-hydrogen efficiency for a dual stacked absorber configuration plotted as a function of the top and bottom photoabsorber band gaps. The top photoabsorber is assumed to be placed above the bottom photoabsorber, thus only photons with energy less than the band gap of the former are transmitted to the latter.

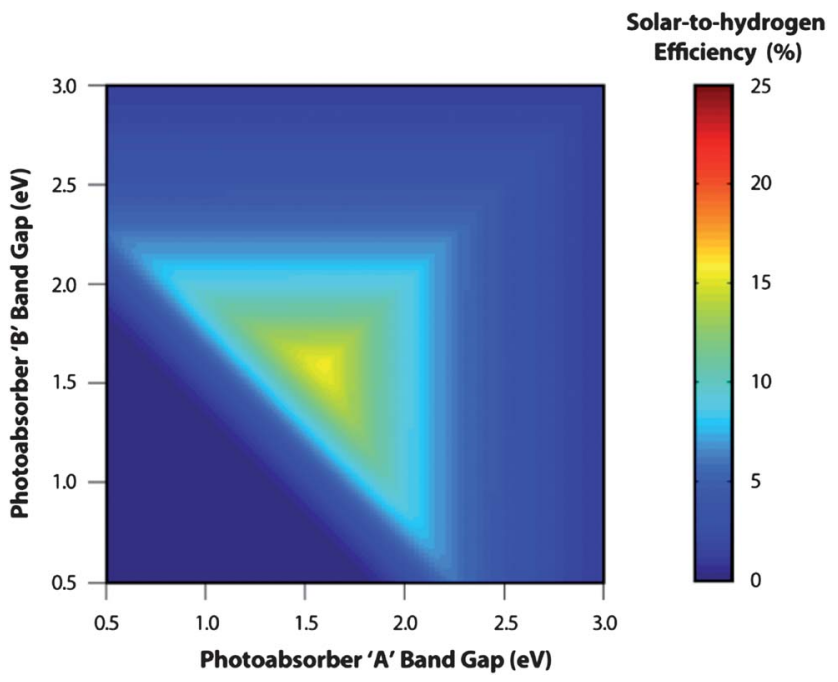

Fig. 4 Maximum theoretical solar-to-hydrogen efficiency for a dual side-by-side absorber configuration plotted as a function of the two photoabsorber (denoted ' $A$ ' and ' $B$ ') band gaps. The two electrodes are assumed to be placed next to each other and can each access the full solar spectrum.

photoabsorber systems, respectively, as a function of the two photoabsorber band gaps. The maximum STH efficiency for a dual stacked absorber system is $22.8 \%$ with bottom and top photoabsorber band gaps of $1.23 \mathrm{eV}$ and $1.84 \mathrm{eV}$, respectively. Once again, this value is considerably lower than the thermodynamic limit of $41 \%$. In comparison, the maximum STH efficiency is $\mathbf{1 5 . 5 \%}$ for a dual side-by-side absorber system with photoabsorbers of the same band gap of $1.59 \mathrm{eV}$. These values provide a baseline from which reasonable device efficiencies can be projected for materials within this range of band gaps. A very important finding is that to achieve efficiencies $>10 \%$, dual absorber systems are likely required. Note that the dual stacked absorber system itself can be configured in more than one way, for instance as either a stacked planar thin film reactor or a particle with two absorber materials. Particles can also be made with only one absorber material, represented by the single absorber system, but that would result in lower attainable efficiencies compared to the dual absorber design. Lastly, the dual side-by-side absorber system is representative of a reactor that uses the added photovoltage of two absorbers, covering twice the area, to achieve the required water splitting voltage. This setup has some advantages over a single absorber system in that less photovoltage is required from each absorber, allowing for use of smaller band gap materials, but it is still not as efficient as a dual stacked absorber system.

\subsection{Demonstrated research efficiencies}

The theoretical calculations above provide realistic limits on PEC water splitting efficiencies based on the performance of modern materials. It is also instructive to consider the best bench scale systems reported in the literature. Bearing both sets of values in mind, efficiencies around which the conceptual solar hydrogen plants will be designed can be selected. Several excellent materials reviews ${ }^{\mathbf{1 5 , 1 6 , 3 4}}$ cover a wide range of published systems while the focus here is on only the highest reported efficiencies for both panel and particle-based systems.

Demonstrated panel electrode solar-to-hydrogen systems generally fit into one of three categories. First are the pure photoelectrochemical systems that are minority carrier devices and have a single or dual PEC junction. The second type is a single PEC junction coupled with either an integrated or external photovoltaic (PV) device. The third category does not contain semiconductor/electrolyte (PEC) junctions and instead involves devices that have separated components, namely a photovoltaic joined with an electrolyzer, potentially in an integrated structure that is immersed into the aqueous electrolyte.

The voltage requirement for solar water splitting using a single absorber in a pure PEC system necessitates the use of a reasonably wide band gap ( $>2.1 \mathrm{eV}$ for an STH efficiency $>5 \%$ ) semiconductor as shown in Fig. 2. Many known materials with band edge potentials that encompass both half-reactions have a valence band edge that is significantly more positive than the water oxidation potential as is the case for the oxides $\mathrm{SrTiO}_{3}$ (ref. 35) and $\mathrm{KTaO}_{4} \cdot{ }^{36}$ Recently a nonoxide, GaN, has demonstrated spontaneous (unbiased) water splitting. ${ }^{37,38}$ All known single junction systems capable of full water splitting absorb only ultraviolet photons, severely limiting their attainable efficiencies in terrestrial PEC systems. Dual PEC electrodes have been demonstrated that are capable of unbiased solar water splitting. Efficiencies are still low when a wide band gap photoanode is employed ${ }^{39}$ but up to $8 \%$ has been measured when two lower band gap III-V materials were coupled together. ${ }^{\mathbf{4 0}}$ This $\mathrm{p}$-InP/n-GaAs system experienced a $10 \%$ drop in relative efficiency over the first hour but maintained constant shortcircuit photocurrent over the next nine hours of operation that were interrupted by extended periods where the electrodes sat in solution in the absence of illumination. 
The second category of devices uses a photovoltaic to overcome energetic barriers at a PEC interface. One particular device utilizes a p-GaInP $\mathrm{P}_{2}$ (photocathode) that makes a PEC junction with the electrolyte. It is synthesized on a $\mathrm{p} / \mathrm{n}$-GaAs photovoltaic and connected via a solid-state tunnel junction to yield a single crystal monolithic device. This system achieved $12.4 \%$ unbiased solar-to-hydrogen efficiency under 12 suns of illumination. ${ }^{6}$ However, over the course of 20 hours the photocurrent declined from $120 \mathrm{~mA} \mathrm{~cm}^{-2}$ to $105 \mathrm{~mA} \mathrm{~cm}{ }^{-2}$. Other PEC/PV systems have combined a metal oxide (photoanode) with a separate photovoltaic, typically a dye-sensitized solar cell ${ }^{41-43}$ and achieved modest efficiencies (2-3\%). ${ }^{44}$ Although the efficiencies were lower, the allure of metal oxide-based systems is that they could be less costly and potentially more stable as photoanodes, though the durability of these systems has not been reported. A $\mathrm{WO}_{3}$ photoanode mechanically stacked on an a-Ge/a-Si tandem PV achieved $0.6 \%$ efficiency under Hawaiian sunlight, but showed signs of degradation after 10 hours of operation. ${ }^{45} \mathrm{~A}$ hybrid photocathode based on a multijunction a-Si PV capped with an a-SiC PEC layer has demonstrated a 1.6\% STH efficiency at zero bias, but the short-circuit photocurrent declined over a short period of testing. ${ }^{46}$

The last category of solar water splitting cells is majority carrier devices that use coupled PV and electrolysis components, where the PV device is either immersed in the electrolyte or separated. In the case of the immersed PV, it is protected from coupling with the electrolyte by an ohmic contact and catalyst, so the electric field that separates photogenerated charges occurs in a buried solid-state $\mathrm{p} / \mathrm{n}$ junction, not at a semiconductor/electrolyte junction. III-V-based systems have achieved efficiencies upwards of $18 \% .{ }^{47-49}$ In the highest reported efficiency systems, the electrode areas responsible for driving the water splitting reactions were much larger than the semiconductor light-absorbing component, which further reduced overpotential losses since those losses are directly related to current density. PEC systems that employ light concentration might be able to accommodate a counter electrode area up to an order of magnitude greater than the absorber. Low-cost systems based on multi-junction a-Si have shown efficiencies up to about $8 \% .^{\mathbf{8 , 9 , 4 8}}$ The PV/electrolysis devices address the instability of a semiconductor/electrolyte interface by eliminating this type of junction but these systems should be compared with completely separated commercial PV and electrolyzers that are independently optimized. Given the significant differences in plant design for this case versus the others, a technoeconomic analysis for this particular scheme was outside the scope of this work. Overall, it is clear that STH efficiencies of approximately $15 \%$ are achievable for panelbased systems, though durability and cost questions remain.

We now consider particle based PEC systems found in the literature which generally fall into one of the three following categories: (i) single particle/single photon water splitting, (ii) two particle/two photon water splitting, and (iii) half-reaction water splitting plus sacrificial reagent and/or nonwater splitting photocatalysts. The efficiencies of these systems are considerably lower than panel devices and are often not directly comparable; literature in this area often reports the external quantum yield (EQY) at a given wavelength rather than the STH efficiency. Here, the definition of the EQY is usually (but not always) reported as shown in eqn (2):

$$
\text { EQY }=\frac{\# \text { of product molecules } \times n}{\# \text { of incident photons }}
$$

where $n$ is the number of electrons transferred per product molecule. Note that there is no accounting for the voltage of a particular reaction or product and thus, overall energy efficiency is not accounted for. The reader is cautioned to make the distinction between the EQY which is more or less analogous to a diagnostic current conversion efficiency and an STH efficiency which is a true power conversion efficiency.

The first category consists of materials capable of driving both the HER and the OER directly with a single absorber particle and without the need for any additional redox reactions. These systems directly drive true water splitting. Barring the employment of multiple exciton generation schemes in these particle systems, quantum efficiencies of photogenerated products are based on absorption of a single photon. The highest EQYs are obtained by using the wider band gap systems, where EQY $>50 \%$ with $E_{\mathrm{g}}=4.1 \mathrm{eV} .^{50}$ Unfortunately, these and other UV-based systems provide little utility under terrestrial solar insolation due to limited absorption and therefore more recent efforts have been devoted toward developing smaller band gap materials. Domen and co-workers have demonstrated true water splitting with an EQY of $2.5 \%$ at $420 \mathrm{~nm}$ using a $\mathrm{Rh}_{2-y} \mathrm{Cr}_{y} \mathrm{O}_{3}$-loaded $\left(\mathrm{Ga}_{1-x} \mathrm{Zn}_{x}\right)\left(\mathrm{N}_{1-x} \mathrm{O}_{x}\right)$, and continue to refine their system. ${ }^{51}$

The second category, often referred to as a 'Z-scheme' system, also drives stoichiometric water splitting but utilizes two separate absorber particles, tuned to drive either the HER or the OER individually. The two half-reactions occurring on separate particles are connected via a reversible, charge transfer redox couple in solution. This system requires twice as many photons to drive water splitting, but offers a higher voltage and broader range of materials choices. Abe and co-workers reported true water splitting with a Z-scheme using $\mathrm{Pt}-\mathrm{SrTiO}_{3}: \mathrm{Cr} / \mathrm{Ta}$ and $\mathrm{Pt}-\mathrm{WO}_{3}$ particles with an $\mathrm{IO}_{3}{ }^{-} / \mathrm{I}^{-}$redox mediator. Stoichiometric $\mathrm{H}_{2}$ and $\mathrm{O}_{2}$ were evolved with an EQY of $\sim 1 \%$ at $420 \mathrm{~nm} .{ }^{52}$ Kudo et al. used a similar $\mathrm{Pt}-\mathrm{SrTiO}_{3}: \mathrm{Rh}$ particle but coupled it with $\mathrm{BiVO}_{4}$ particles and an $\mathrm{Fe}^{3+/ 2+}$ redox mediator and reported an EQY of $0.3 \%$ at $440 \mathrm{~nm}$. Here, both particles had a band gap of $2.4 \mathrm{eV}$. Fujihara et al. devised a system using separate compartments loaded with $\mathrm{TiO}_{2}$ particles, one side driving the HER and the oxidation of $\mathrm{Br}^{-}$to $\mathrm{Br}_{2}$, the other compartment driving the OER with concurrent reduction of $\mathrm{Fe}^{3+}$ to $\mathrm{Fe}^{2+}$ to yield overall water splitting. ${ }^{53}$

The third category described in the literature encompasses a very broad range of particulate PEC design types but differs in that true, stoichiometric water splitting via the HER and the OER is not driven. Fundamentally, the optoelectronics can be the same as the first and/or second categories described above, but the significant difference is found in the thermodynamics of the redox reactions which are catalyzed. In this category, the free energy $(\Delta G)$ of reaction differs from that required for true water splitting. In practice, the $\Delta G$ of the reactions chosen is 
typically smaller than that required for water splitting ${ }^{50,54}$ or, in some reported PEC systems, negative and therefore thermodynamically favored. ${ }^{50}$ These systems may find application in photocatalytic decomposition of organic pollutants to clean air or water ${ }^{55}$ and could offer fundamental mechanistic insight into the dynamics of complex PEC systems, but they will not be discussed here as the primary goal of this work is to address the feasibility of converting and storing photon energy in the chemical bonds of $\mathrm{H}_{2}$ and $\mathrm{O}_{2}$.

\section{Reactor design descriptions}

The centralized plant designs based on four reactor types, named Type 1, 2, 3, and 4, were conceived by the DOE PEC Working Group. These four configurations do not represent all possible types of systems but are meant to represent a range of complete, albeit basic, designs of potentially realizable systems for the purpose of preliminary technical and economic evaluation. Each system incorporates all components required to absorb solar photons, generate adequate voltage to evolve $\mathrm{H}_{2}$ and $\mathrm{O}_{2}$ from water, and collect and compress only the $\mathrm{H}_{2}$ product. The reactors can be grouped into one of two general classes, namely particle suspensions or planar arrays. The Type 1 and Type 2 systems are enclosed aqueous reactor beds of suspended photoactive particles while the Type 3 and Type 4 systems consist of multilayer absorber planar arrays immersed in an aqueous electrolyte and oriented toward the sun. This section describes the four reactor configurations and outlines key assumptions about their performance in light of the calculations and state of the art described previously.

\subsection{Type 1 reactor: single bed particle suspension}

The Type 1 reactor is the simplest of the four and consists of a low-lying horizontal plastic bag, termed henceforth a 'baggie', containing a slurry of photoactive particles in a $0.1 \mathrm{M}$ potassium hydroxide ( $\mathrm{KOH})$ electrolyte. The plastic baggie is designed to retain the electrolyte, photoactive particles, and evolved gases while allowing light to penetrate. A schematic of the design for a Type 1 reactor is shown in Fig. 5(a). High density polyethylene (HDPE) is selected for both the transparent upper layer and opaque bottom liner due to its high optical transmission (90\%), low hydrogen permeability ( $156 \mathrm{~cm}^{3} \mathrm{~mm}$ per $\mathrm{m}^{2}$ atm per day), ${ }^{56}$ resistance to degradation in an alkaline electrolyte, and low cost. The size of each baggie is $323 \mathrm{~m}$ long by $12.2 \mathrm{~m}$ wide. These dimensions were chosen because they are as large as possible while enabling the baggie segments to be produced as single sheets of plastic using existing manufacturing technology and easily transported on large rolls using a standard $16.8 \mathrm{~m}$ truck. Two plastic sheets are laminated together to construct the baggie. Upon filling the baggie with the aqueous particle slurry, the upper portion of the envelope initially rests on the liquid surface. This upper portion will rise and fall as gas is generated and drawn off. Gas accumulates in the extra volume and is stored in the headspace during the daylight $\mathrm{H}_{2}$ production phase to level the load on the purification and compression equipment required for this design. Since the baggie is completely sealed, water vapor is not vented to the atmosphere. Preventing evaporative cooling in this way allows the beds to operate at temperatures above $60{ }^{\circ} \mathrm{C}$ in summer which slightly reduces the thermodynamic voltage for water splitting but this effect may be offset by a decrease in efficiency due to greater entropic losses in the absorber.

The photoactive particles are modeled as conductive spherical cores (40 nm diameter) coated with photoanodic and photocathodic materials ( $\sim 5 \mathrm{~nm}$ layers) as islands, particles, or thin film shells. The primary motivation for selecting this particle design is to consider the cost of a relatively complex composition and morphology. One could also envision a photoactive particle at the core coated with only one additional absorber layer. The particle geometry could also take the form of a photoabsorbing core with co-catalysts for both the HER and the OER. In this case, $\mathrm{H}_{2}$ and $\mathrm{O}_{2}$ evolution occur simultaneously on the surface of a single particle which produces a mixed gas stream which must be purified. The required unit operations for this purification step are described later. The cogeneration of $\mathrm{H}_{2}$ and $\mathrm{O}_{2}$ in stoichiometric quantities results in a combustible mixture and engineering controls will be needed to mitigate this serious safety risk.

Preliminary analysis conducted at the University of California at Santa Barbara suggests a $10 \mathrm{~cm}$ deep particle suspension is appropriate for full light absorption when considering light scattering and typical values for semiconductors with indirect band gaps or low absorption coefficients. The layered structure of the photocatalyst particles is akin to a dual stacked configuration which has a calculated maximum theoretical STH efficiency of $22.8 \%$, assuming high quality semiconductors and highly active catalysts, but so far experimentally demonstrated particle systems have fallen far short of this limit. Thus, a more conservative baseline STH efficiency of $10 \%$ was used for the technoeconomic analysis.

\subsection{Type 2 reactor: dual bed particle suspension}

The Type 2 reactor (Fig. 5(b)) shares many characteristics of the Type 1 reactor. The primary difference is the use of separate beds for $\mathrm{O}_{2}$ and $\mathrm{H}_{2}$ production which affords two general benefits: (i) intrinsic separation of the two gases, which improves plant safety while reducing needs for gas separation in the processing sub-assembly, and (ii) greater flexibility in the semiconductor properties needed for effective water splitting. This design, however, requires the use of a redox mediator $\left(\mathrm{A} / \mathrm{A}^{-}\right)$and porous bridges to transport it from one compartment to the other. The equations for water splitting now become as follows:

$$
\begin{gathered}
\mathrm{O}_{2} \text { evolution bed: } 4 h \nu+2 \mathrm{H}_{2} \mathrm{O}+4 \mathrm{~A} \rightarrow \mathrm{O}_{2}+4 \mathrm{H}^{+}+4 \mathrm{~A}^{-} \\
\mathrm{H}_{2} \text { evolution bed: } 4 h \nu+4 \mathrm{H}^{+}+4 \mathrm{~A}^{-} \rightarrow 2 \mathrm{H}_{2}+4 \mathrm{~A}
\end{gathered}
$$

The redox mediator could be any species exhibiting rapid, reversible reactivity and large diffusivity in either redox state, such as iodine, bromine, or iron complexes. The absorber in this system is modeled as spherical substrate particles $(40 \mathrm{~nm}$ 

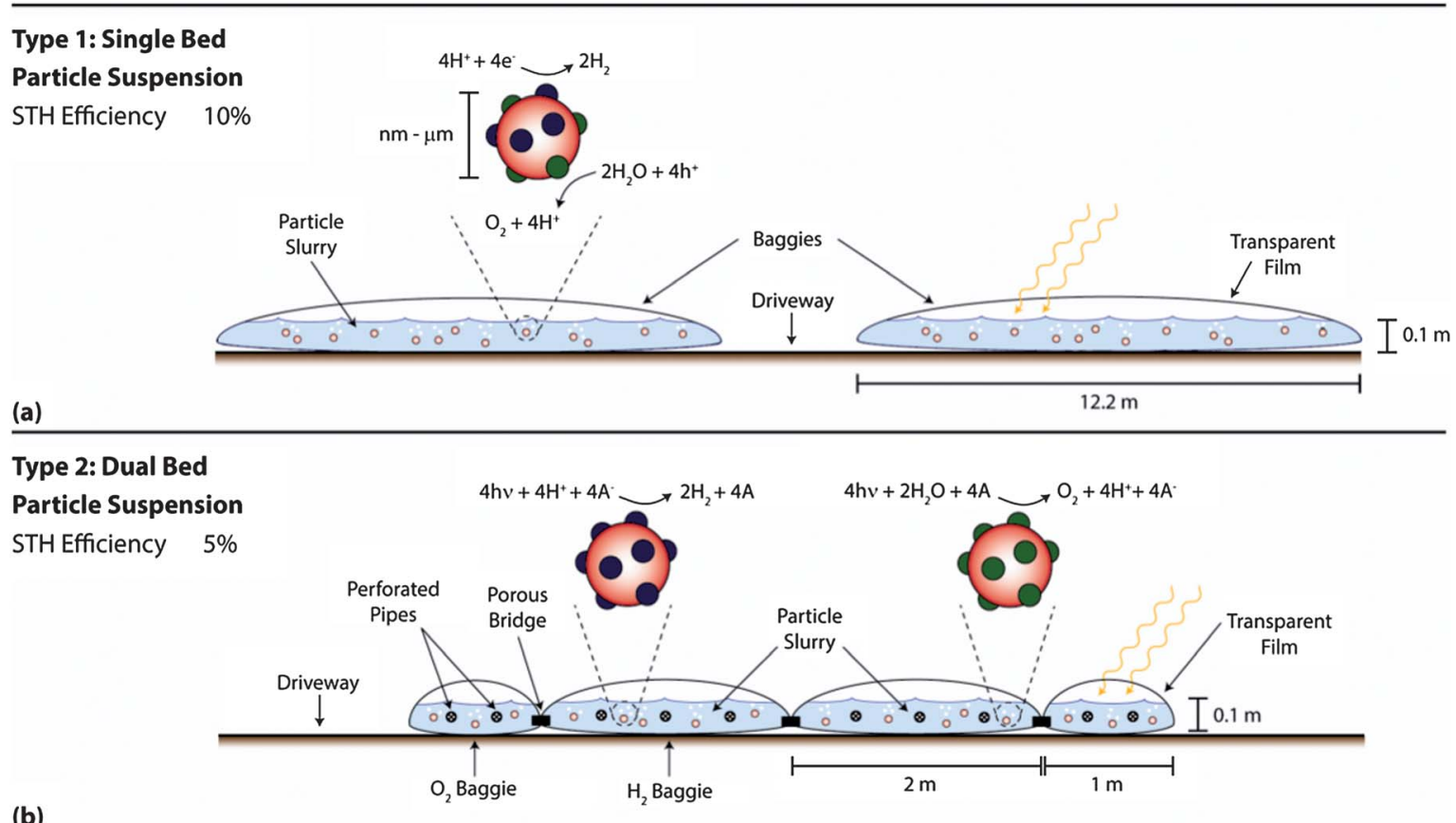

(b)

Type 3: Fixed

Panel Array

STH Efficiency $\quad 10 \%$

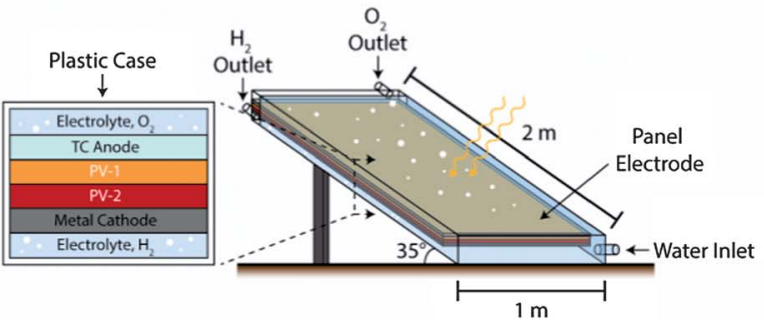

(c)

Type 4: Tracking
Concentrator Array
STH Efficiency $\quad 15 \%$

(d)

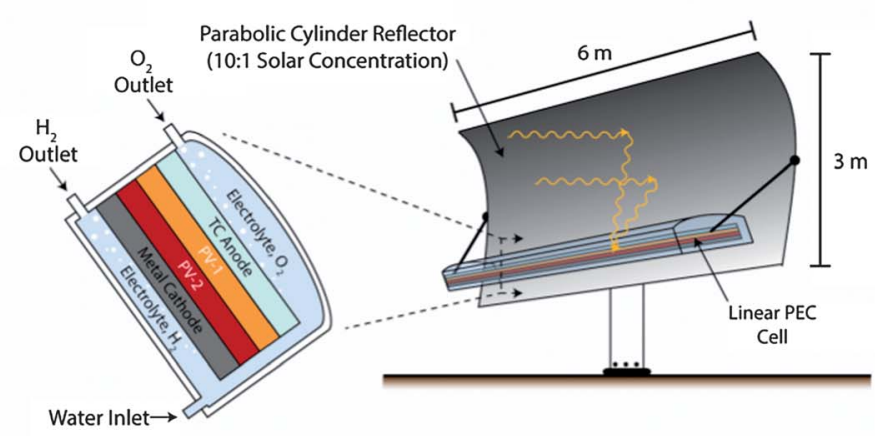

Fig. 5 Schematic of the four reactor types including (a) Type 1 reactor cross-section showing the particle slurry contained within baggies separated by an access driveway, (b) Type 2 reactor cross-section showing the particle slurries contained within baggie assemblies consisting of an alternating arrangement of a full size and half-size baggie each for $\mathrm{O}_{2}$ and $\mathrm{H}_{2}$ evolution, (c) Type 3 reactor design showing the encased composite panel oriented toward the sun with buoyant separation of gases, and (d) Type 4 reactor design with an offset parabolic cylinder receiver concentrating light on a linear PEC cell. Drawing not to scale.

diameter) with a single photoactive layer deposited over the surface. Once again, this geometry is selected for costing purposes but many other viable options exist such as a photoactive core decorated with a co-catalyst. Continuous slurry circulation through perforated pipes running the length of the baggies facilitates mixing and transport of the redox mediator. Feed-through bridges located below the gas/liquid interface are provided between the $\mathrm{H}_{2}$ and $\mathrm{O}_{2}$ production beds with a porous membrane running the entire length of the baggies. These allow transport of the redox mediator but prevent gas migration. Each bed assembly comprises a full and a half-size baggie each for $\mathrm{O}_{2}$ and $\mathrm{H}_{2}$ evolution, as shown in Fig. 5(b), to minimize the distance between complementary reaction sites. The total assembly dimensions are $61.0 \mathrm{~m}$ long by $6.1 \mathrm{~m}$ wide; the decrease in width from the Type 1 baggies further reduces transport distances and the decrease in length facilitates 
attaching porous bridges. Decoupling of the HER and the OER onto separate particles requires twice the photon capture area of the Type 1 system and is analogous to the side-by-side configuration for which the upper efficiency limit computed was $15.5 \%$. Again, a more conservative value is selected for the baseline technoeconomic analysis; the assumed net STH efficiency for this system is $5 \%$. Better solar utilization and thus a higher water splitting efficiency could be achieved by stacking the baggies one on top of the other rather than positioning them side-by-side. While potentially interesting, this embodiment was not considered in this analysis.

\subsection{Type 3 reactor: fixed panel array}

A great deal of experimental research to date has focused on planar photoelectrodes immersed in solution, either with an integrated cathode and anode or with spatially separated electrodes. The Type 3 and 4 reactors reflect this design archetype with photocells closely resembling commercial photovoltaics. The Type 3 reactors (Fig. 5(c)) feature an integral planar electrode with multiple photoactive layers sandwiched between two electrodes. The entire assembly is encased in a transparent plastic electrolyte reservoir containing $0.1 \mathrm{M} \mathrm{KOH}$. Poly(methyl methacrylate) (PMMA) is selected for its high optical transmission, mechanical strength, and resistance to chemical degradation in basic electrolyte and serves as a good starting point for costing. Individual cells, as large as can be readily manufactured, are assembled to form panels $1 \mathrm{~m}$ wide and $2 \mathrm{~m}$ long. The panels are tilted toward the Earth's equator and are oriented at an angle from the horizontal equal to the local latitude for optimal solar photon collection over the course of the entire year. Two layers of photoactive material are used to maximize solar spectrum utilization and provide the requisite voltage to split water. $\mathrm{O}_{2}$ evolution occurs on a transparent conducting (TC) anode which allows photons to pass through and be absorbed in the two underlying photoactive layers. The bottom of the stack is composed of a metal cathode where electrons are collected to drive $\mathrm{H}_{2}$ evolution. Gas separation is achieved by the physical partitioning of the $\mathrm{O}_{2}$ and $\mathrm{H}_{2}$ reaction sites and separate buoyant collection of the gases can be exploited due to the inclination of the panel. A depiction of the cell stack composition and orientation is shown in Fig. 5(c). In terms of maximum theoretical efficiencies, this system closely resembles the stacked configuration of Type 1 so a conservative STH efficiency of $10 \%$ is used for the baseline cost calculations.

\subsection{Type 4 reactor: tracking concentrator array}

A tracking concentrator system maximizes the direct radiation capture and enables the use of higher efficiency, higher cost materials because the photocell area is greatly reduced. The Type 4 reactor (Fig. 5(d)) uses an offset parabolic cylinder array to focus sunlight on a linear PEC cell receiver and has 2-axis steering to track the daily movement of the sun. This style of concentrator was selected to keep costs low, reduce weight, and because it allows the photoreactor, water feed, and $\mathrm{H}_{2}$ collection piping to be located in the reflector base assembly. Each concentrator array is $6 \mathrm{~m}$ wide and $3 \mathrm{~m}$ in height. A laboratory- demonstrated solar concentration ratio of $10: 1$ is used for the analysis, though higher ratios would further reduce reactor costs. Multijunction photovoltaics can operate at solar concentration ratios upwards of $400: 1$ (ref. 57) but PEC cells are limited by the ability of a catalyst to drive current densities above $1 \mathrm{~A} \mathrm{~cm}^{-2}$, light scattering due to bubble formation, and temperature constraints for moderate cost materials. A ratio of $100: 1$ is likely an upper limit ${ }^{6}$ and a more conservative value of $10: 1$ is adopted for this analysis. The smaller volume electrolyte reservoir allows direct pressurization of the electrolyte and gases to 300 psi using the inlet water pump, precluding the need for a separate compressor for the $\mathrm{H}_{2}$ gas product. Added benefits of pressurization include minimizing water vapor loss and reducing gas bubble size and the associated detrimental photon scattering. The PMMA window is made cylindrical to reduce stress arising from the increased operation pressure and to focus light on the PEC cells. An additional benefit of the $10: 1$ concentration is an increased efficiency due to the larger maximum photovoltage. The photocell stacks have the same general composition as in the Type 3 reactor but allow for more expensive, high quality materials to be used since the photon capture area is reduced. Higher quality materials will likely result in better performance so the assumed STH efficiency is raised to $15 \%$, consistent with calculated efficiencies for a dual stacked absorber system (Fig. 3) and well within the range of previously reported high efficiency $\mathrm{PV}^{-\mathrm{PEC}^{6}}$ and integrated PVelectrolysis $^{47,48}$ devices that operate between 12 and $18 \%$ STH efficiency.

\subsection{Reactor design limitations}

Each reactor design described above has its limitations. The Type 1 and Type 2 reactors are relatively simple. However, compared to the planar electrode designs there is greater uncertainty associated with the fabrication of the photoactive particles as well as much lower demonstrated bench-scale efficiencies. There is also a lack of understanding of the effective photon capture area per particle and particle density required for total solar flux utilization. Partial shading of particles deeper in the bed is also problematic as it will result in a lower effective incident light intensity reaching these deep particles and thus lower performance due to a decrease in their maximum photovoltage. Further testing and modeling of these systems is required.

The large size of the Type 1 baggies may present practical limitations in that a failure in the mechanical integrity (due to weather, bird damage, etc.) of a single baggie would result in a significant release of electrolyte and plant capacity loss. Mitigating this concern by decreasing the size of the baggies, which would require a greater number of baggies, is likely to increase the costs associated with this system. The Type 2 system has additional limitations in that mediator transport rates across the bridges and associated voltage losses are uncertain. More bridges may be needed to overcome these challenges, which would increase system costs. It is also not trivial to guarantee the presence of solely $\mathrm{O}_{2}$ or $\mathrm{H}_{2}$ in each baggie if there is undesired gas transport across the bridges. Also, the simultaneous 
evolution of both gases on the particles in a single baggie could be a problem if the band positions of the absorbers and catalyst selectivities are not ideal.

In contrast to the particulate systems, the Type 3 and Type 4 systems are considerably more complex. The higher current densities drawn on the much smaller photocell of the Type 4 system will require high performing HER and OER catalysts. This more stringent catalyst requirement could be mitigated by increasing the surface area for catalysis while preserving the smaller absorber area; however, decoupling of the absorber and catalyst areas presents additional design challenges and costs. Given the large scale of all the reactors, there may be a significant voltage loss due to the voltage drop across the solution. ${ }^{58}$ The size of the baggies for particulate systems may need to be reduced or additional transport channels introduced in planar electrodes to minimize these losses.

Note that the planar array PEC reactors described here can just as easily be applied to integrated PV-electrolysis units. Both of these options have advantages over a system composed of a commercially available photovoltaic cell connected to a conventional water electrolyzer. The costs associated with the contacts for current collection, charge conditioning and current transmission losses in the latter are eliminated. Photon capture over a large area in the case of the PEC reactors or PV-electrolysis units also relaxes the catalyst requirements, enabling the use of inexpensive nonprecious metal catalysts. The particles or electrodes have large areas where current densities on the order of $\mathrm{mA} \mathrm{cm}{ }^{-2}$ rather than $\mathrm{A} \mathrm{cm}^{-2}$ are drawn, requiring a lower voltage to drive the OER and the HER than in a conventional electrolyzer. In addition, unknown complications (e.g. product crossover) may arise in electrolyzers operating at these decreased current densities because electrolyzers are traditionally operated at larger current densities.

Nevertheless, there exists the opportunity to design improved nonintegrated PV-driven electrolysis. As solar absorption and catalysis can be decoupled with such a system, semiconductors unstable in aqueous environments could be considered. As the analysis presented in this work is limited to systems in which the semiconductor is directly immersed in the electrolyte, the technoeconomics of PV-driven electrolysis is outside of the scope. A similar analysis for such an approach would be welcomed by the community.

\section{Plant design and operation}

Complete PEC hydrogen production plants were designed based on the dimensions, operating conditions, and performance characteristics of the four reactor types. To enable accurate cost analysis, these plant designs incorporated all the unit operations necessary to deliver a purified and compressed hydrogen gas product. The plant designs include the reactor layout and spacing, gas processing components, control systems, and support piping and wiring. Each plant module consists of reactor arrays and gas separation/compression equipment sized to deliver 1 tonne per day (TPD) of $\mathrm{H}_{2}$ at $300 \mathrm{psi}$ (20.4 atm). The pipeline pressure was selected to be directly comparable with other DOE H2A Production Plants. Note that in the Type 1 system where there are $\mathrm{H}_{2}$ losses associated with the gas separation process, the reactor arrays are sized to deliver a net production of 1 TPD $\mathrm{H}_{2}$ after separation. For the purposes of the cost analysis, an entire $\mathrm{H}_{2}$ production plant will consist of 10 of such systems for a total net production of 10 TPD.

\subsection{Solar insolation}

An accurate measure of photon flux is necessary to size the plants and determine the reactor layouts. A hypothetical plant site of Daggett, CA, USA, at $35^{\circ}$ North latitude, was assumed for the purposes of determining the insolation. This location was chosen because it is the most favorable of the 239 National Solar Radiation Database sites due to its high terrestrial insolation and minimal cloud cover. The solar insolation model considered both direct and diffuse radiation as a function of time of the day and day of the year. The different reactor types utilize these sources of radiation with different efficiencies. The NREL SOLPOS model was used to calculate the extraterrestrial radiation (ETR) intensity and solar position. The clearness index, defined as the average loss due to atmospheric absorption, scattering, and cloud cover, was derived from the NREL Solar Radiation Data Manual. To determine the direct insolation intensity, the ETR was multiplied by the clearness index. The total insolation on the Type 1, Type 2, and Type 3 systems was the sum of the direct and diffuse components whereas the Type 4 system used only the direct solar component. The amount of incident radiation that is captured depends on the reactor design, specifically the orientation and type of covering (HDPE vs. PMMA). Fig. 6 shows the average monthly insolation calculated for the different reactor types. The insolation and the STH efficiency assumptions outlined in Section 3 were used to determine the reactor array sizes required to achieve an average annual production of $1 \mathrm{TPD} \mathrm{H}_{2}$. All reactors and plants were designed to accommodate variations in the hydrogen production rate due to changes in irradiance over the course of a day and throughout the year. However, the daily output of hydrogen varies substantially over a year, which may not match market

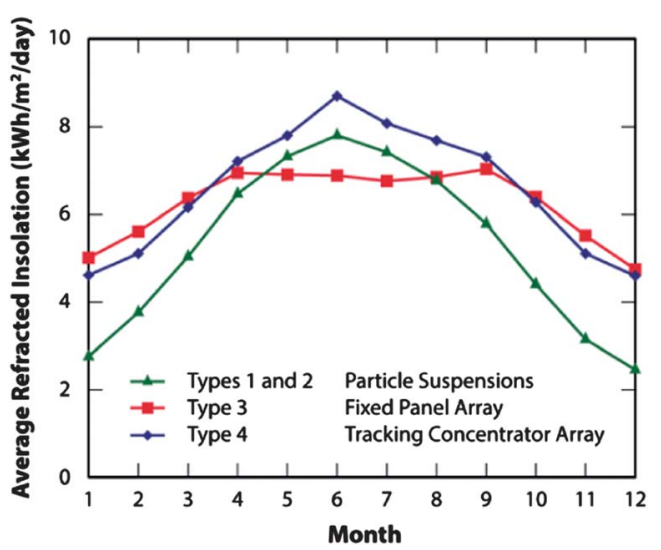

Fig. 6 Average monthly refracted insolation for each reactor type. Refracted insolation refers to the light intensity incident upon the photoabsorbers, as opposed to the incident intensity (not shown), which is incident upon the HDPE or PMMA reactor covering. 
demand for the hydrogen product. A summary of the pertinent parameters for each system design and plant layout is shown in Table 1 while additional details follow below.

\subsection{Type 1 plant design: single bed particle suspension}

A horizontal plate field geometry with a solar input including direct and diffuse radiation was used to model the suspension bed and the average yearly insolation calculated for this reactor type was $5.77 \mathrm{~kW} \mathrm{~h}$ per $\mathrm{m}^{2}$ per day. Based on this yearly insolation and the STH efficiency estimate of 10\%, 18 baggies of $323 \mathrm{~m} \times 12.2 \mathrm{~m}$ each are required for a net production of $1 \mathrm{TPD}$ $\mathrm{H}_{2}$. The layout of the plant was designed to minimize the spacing between the baggies for optimal land use. Some space was left between the reactors for maintenance access and a total of $30 \%$ additional land area was allocated for auxiliaries. Because these reactors are very wide and short, solar shadowing was not a consideration. A top-view diagram illustrating the plant layout is shown in Fig. 7(a). The reactors are integrated with the gas processing subassembly via ports in each HDPE baggie that allow for water input and gas output. This embodiment is the only one of the four selected for evaluation which results in a combustive mixture of stoichiometric $\mathrm{H}_{2}$ and $\mathrm{O}_{2}$. Compression of this explosive mixture is considered a very important design concern but not an insurmountable problem.

\subsection{Type 2 plant design: dual bed particle suspension}

The Type 2 plant design is very similar to the Type 1 plant design. Pure $\mathrm{O}_{2}$ and $\mathrm{H}_{2}$ are now produced in separate compartments, so the need for gas separation equipment is obviated. This configuration also significantly reduces the risks associated with inadvertent $\mathrm{H}_{2} / \mathrm{O}_{2}$ gas combustion. The same set of assumptions was used to calculate the average yearly insolation, $5.77 \mathrm{~kW} \mathrm{~h}$ per $\mathrm{m}^{2}$ per day. Accounting for the $\mathrm{STH}$ efficiency of $5 \%, 347$ assemblies of $61.0 \mathrm{~m} \times 6.1 \mathrm{~m}$ each are required to produce $1 \mathrm{TPD} \mathrm{H}_{2}$. The layout of this plant is also designed to maximize land usage while allowing some space between the assemblies for maintenance access and auxiliaries, estimated to be $30 \%$ additional area. As with the previous reactor type, solar shadowing is not a concern. A diagram illustrating the plant layout is shown in Fig. 7(b). Once again, water input and gas output are accomplished by ports in the HDPE baggies.

\subsection{Type 3 plant design: fixed panel array}

As with the Type 2 system, because the $\mathrm{O}_{2}$ and $\mathrm{H}_{2}$ are produced in separate compartments, no gas separation process is required and the safety concerns associated with inadvertent gas combustion are minimized. To maximize the solar radiation captured, the fixed planar panels are tilted toward the South at an angle equal to the plant latitude. Using a $35^{\circ}$ tilted array geometry for Daggett, California and assuming a solar input including direct and some diffuse radiation, the average yearly insolation calculated for this reactor type is $6.19 \mathrm{~kW} \mathrm{~h}$ per $\mathrm{m}^{2}$ per day. With an STH efficiency of 10\%, a total of 26923 panels each $1 \mathrm{~m}$ wide and $2 \mathrm{~m}$ long are required to achieve a target production of $1 \mathrm{TPD} \mathrm{H}_{2}$. The layout of this plant is designed to minimize the effects of solar shadowing by adjacent panels. The North-South panel spacing is set such that there is no shadowing at sun angles greater than $10^{\circ}$ above the horizon. Based on the panel dimensions, this requires a separation distance of $8.1 \mathrm{~m}$, resulting in an emplacement area ratio of $4.07 \mathrm{~m}^{2}$ land per $\mathrm{m}^{2}$ panel. A diagram illustrating the plant layout is shown in Fig. 7(c). The water input and gas outputs are connected to manifolds that lead to large central collection pipes.

\subsection{Type 4 plant design: tracking concentrator array}

In this system, the water input is pressurized and the $\mathrm{O}_{2}$ and $\mathrm{H}_{2}$ are produced in separate compartments. Therefore, neither gas separation nor compression is required. The concentrator array angle in the Type 4 system is controlled so that the panels point

Table 1 Summary of hydrogen output of a net 1 TPD plant module for each of the four conceptual PEC hydrogen production plants with values for the solar input, system efficiencies, reactor dimensions, and emplacement area

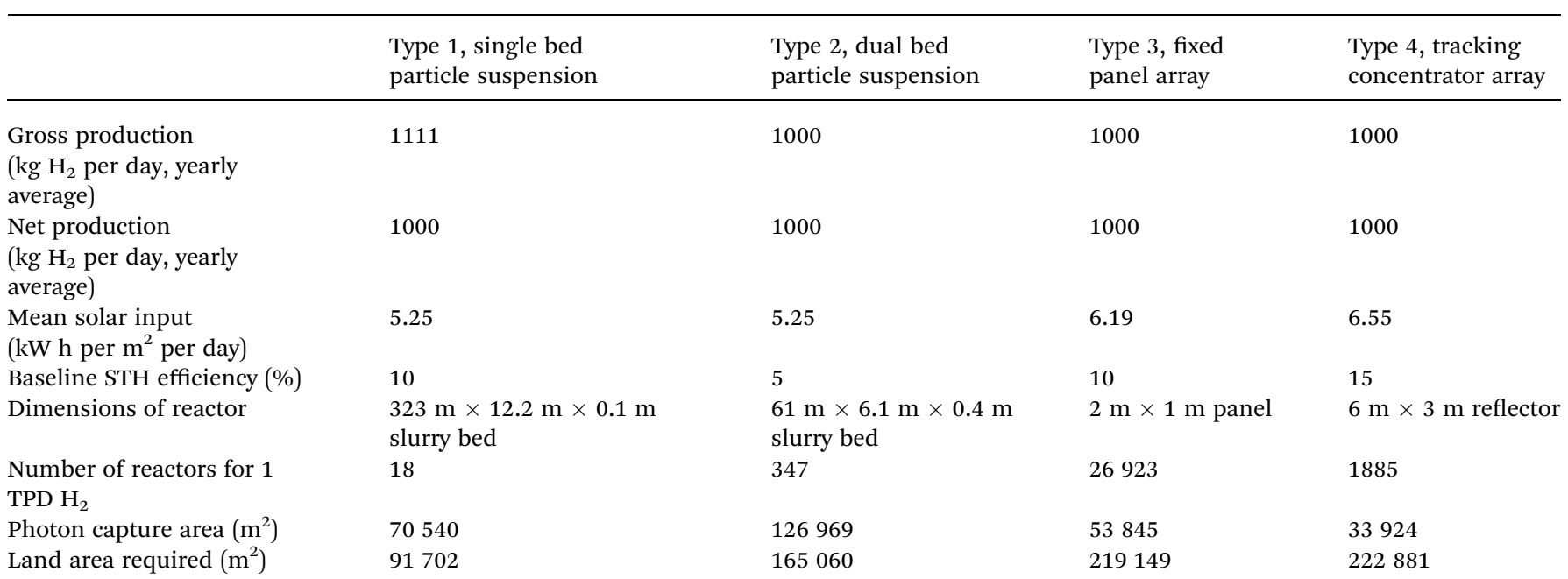




\section{Type 1: Single Bed Particle Suspension Plant Area $91,702 \mathrm{~m}^{2}$}

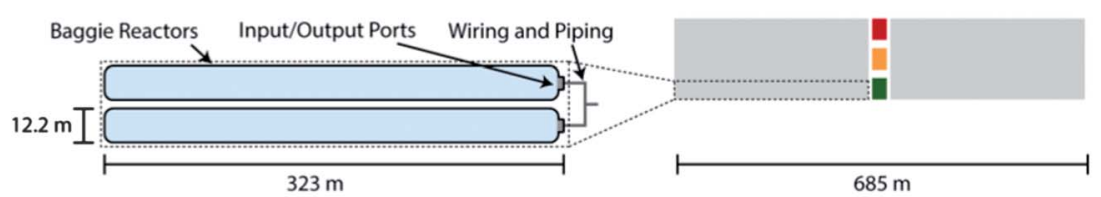

(a)

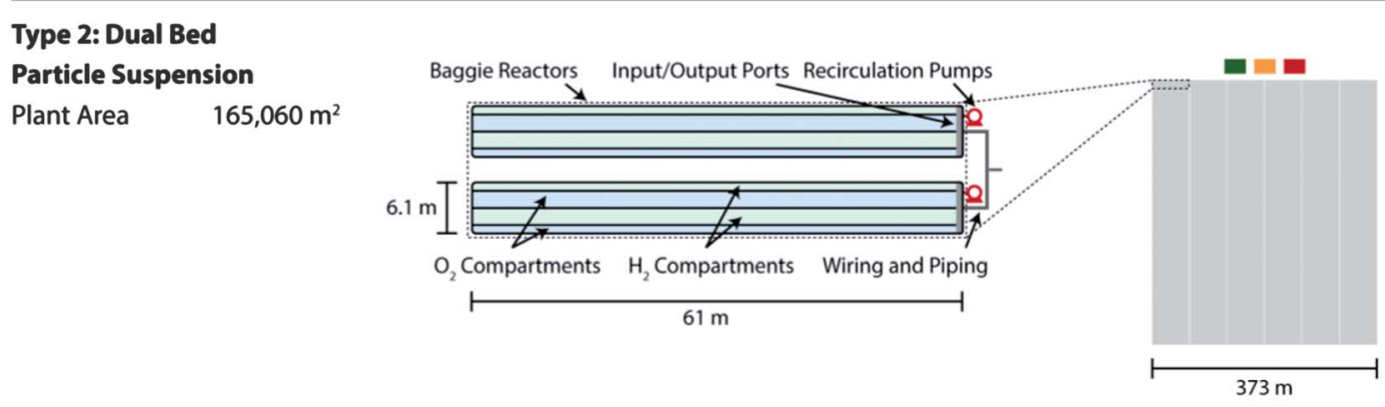

(b)

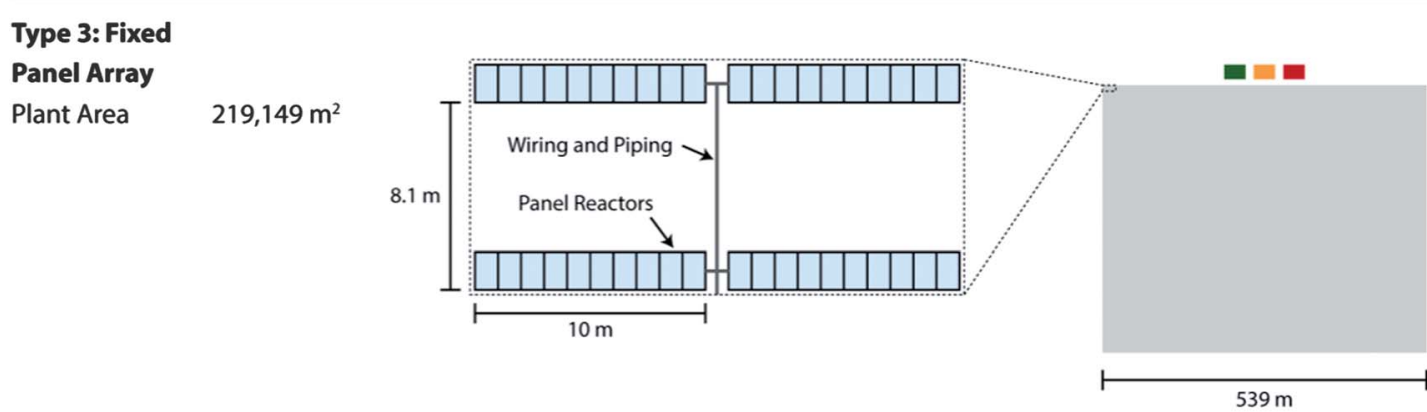

(c)

Type 4: Tracking
Concentrator Array
Plant Area $\quad 222,881 \mathrm{~m}^{2}$

(d)

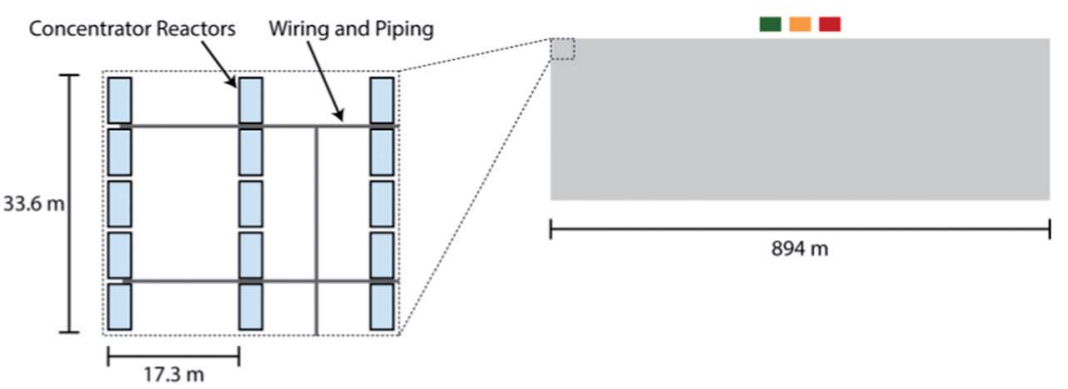

Fig. 7 Plant module layout of reactor arrays for 1 TPD $\mathrm{H}_{2}$ production for reactors (a) Type 1, (b) Type 2, (c) Type 3, and (d) Type 4. A make-up water subassembly provides water flow to the reactors, the gas processing subassembly purifies and compresses (if needed) the product gas while the control room is used for monitoring. These unit operations are centralized and driveways provide access to the individual beds or reactor arrays. Panel array emplacement is designed to minimize shadowing.

directly toward the sun throughout the day. This tracking system captures the direct radiation very effectively, but due to the shape of the concentrators, collection of diffuse radiation is minimal. These assumptions lead to an average yearly insolation of $6.55 \mathrm{~kW} \mathrm{~h}$ per $\mathrm{m}^{2}$ per day for this reactor type. With an STH efficiency of $15 \%$, a total of 1885 concentrator arrays each 6 $\mathrm{m}$ wide and $3 \mathrm{~m}$ in height are required to produce $1 \mathrm{TPD} \mathrm{H}_{2}$. The spacing between the concentrator arrays was again determined to minimize the effects of shading by adjacent concentrators. In this case, because the arrays track the sun, the spacing along both the North-South and East-West axes was considered. The arrays are spaced such that there is no shadowing when the sun is more than $10^{\circ}$ above the horizon in the East-West direction or $26^{\circ}$ above the horizon to the South. The necessary spacing was $6.71 \mathrm{~m}$ in the North-South direction and $17.3 \mathrm{~m}$ in the EastWest direction, resulting in an emplacement area ratio of 
Table 2 Summary of liquid and gas handling systems required for each reactor type

\begin{tabular}{|c|c|c|c|c|}
\hline & $\begin{array}{l}\text { Type } 1 \text {, single bed particle } \\
\text { suspension }\end{array}$ & $\begin{array}{l}\text { Type } 2 \text {, dual bed particle } \\
\text { suspension }\end{array}$ & Type 3 , fixed panel array & $\begin{array}{l}\text { Type } 4 \text {, tracking } \\
\text { concentrator array }\end{array}$ \\
\hline Piping & $\begin{array}{l}14.7 \text { psia water inlet, gas } \\
\text { outlet }\end{array}$ & $\begin{array}{l}14.7 \text { psia water inlet, gas } \\
\text { outlet, electrolyte circulation }\end{array}$ & $\begin{array}{l}14.7 \text { psia water inlet, } \\
\text { gas outlet }\end{array}$ & $\begin{array}{l}300 \text { psia water inlet, } \\
\text { gas outlet }\end{array}$ \\
\hline Compression & 305 psia $\mathrm{H}_{2}, \mathrm{O}_{2}$, water vapor & 300 psia $\mathrm{H}_{2}$, water vapor & 300 psia $\mathrm{H}_{2}$, water vapor & Not required \\
\hline $\begin{array}{l}\text { Condensation } \\
\text { and cooling }\end{array}$ & $\begin{array}{l}\text { Reactor outlet, condenser, } \\
\text { dual intercoolers }\end{array}$ & $\begin{array}{l}\text { Reactor outlet, condenser, } \\
\text { dual intercoolers }\end{array}$ & $\begin{array}{l}\text { Reactor outlet, condenser, } \\
\text { dual intercoolers }\end{array}$ & Reactor outlet, condenser \\
\hline Purification & $\begin{array}{l}\text { Pressure swing adsorption to } \\
\text { remove } 33 \text { molar } \% \mathrm{O}_{2}\end{array}$ & Not required & Not required & Not required \\
\hline
\end{tabular}

$6.57 \mathrm{~m}^{2}$ of land per $\mathrm{m}^{2}$ concentrator. A diagram illustrating the plant layout is shown in Fig. 7(d). The water input and gas outputs are connected via manifolds to central collection pipes.

\subsection{Gas processing and control system subassemblies}

In addition to the reactors, the plants also include subassemblies for separating, purifying, and compressing the product gas streams and controlling the reactor operation. The basic components are similar for Types 1-4, but due to the specifics of each design, not all elements are required for each reactor type. These subassemblies are supported by extensive piping and wiring. All piping in the designs consists of polyvinyl chloride to minimize costs. The effects of hydrogen embrittlement and gas diffusion are assumed to be negligible given the moderate temperature and pressure operating conditions.

The hydrogen delivered from each plant is purified and compressed to $300 \mathrm{psi}$. The gas processing subassembly, which includes compression, separation, and purification unit operations, is used to condition the hydrogen. Prior to compression, the gas stream for the Type 1, Type 2, and Type 3 systems is cooled to $40{ }^{\circ} \mathrm{C}$ with a cooler/condenser to remove water vapor and reduce the volumetric flow to the compressor. A two-stage oil free piston compressor with intercooling is selected for the compression unit operation. For the Type 1 system, the outlet $\mathrm{O}_{2} / \mathrm{H}_{2}$ gas is compressed to 305 psi to allow for the 5 psi pressure loss associated with separation of the product gases. The yearly average plant size is 1 TPD and without interim compressed $\mathrm{H}_{2}$ storage facilities, the compressors are sized to handle the peak $\mathrm{H}_{2}$ output and will operate at reduced capacity most of the year. For Types 1 and 2, this output is the average daily production on June 21 because the baggies have the capacity to expand to accumulate excess gas in the bed headspace over the 24 hour day. For the Type 3 system, the compressor is sized for the instantaneous peak output at noon on June 21 because there is no space for accumulation. Given the additional volume of the $\mathrm{O}_{2}$ in the product stream, the Type 1 compressor must handle 1.5 times the volume flow when compared to the Type 2 and 3 compressors. The Type 4 reactor does not require an additional compression stage because the $\mathrm{H}_{2}$ exits the reactor at 300 psi so only a condenser is needed at the gas outlet to separate water vapor.

Commercial methods considered for separating out the $\mathrm{H}_{2}$ in the product stream of the Type 1 reactor include pressure swing adsorption (PSA), temperature swing adsorption (TSA), palladium membrane separation, nano-porous membrane separation, and electrochemical pumps. PSA, frequently employed for the separation of $\mathrm{H}_{2}$ from steam methane reforming product gases, was selected as the best option to separate a mixture of $\mathrm{H}_{2}, \mathrm{O}_{2}$, and $\mathrm{H}_{2} \mathrm{O}$ for the following reasons: lower cost, higher technological maturity, reduced cycle time, lower temperature and pressure requirements, and no need for additional gas cleanup processes. PSA purification proceeds by flowing the pressurized mixed stream over an absorbent bed designed to capture the undesired gas while $\mathrm{H}_{2}$ continues flowing through the system; a carbon sorbent is used for $\mathrm{O}_{2}$ and silica gel for $\mathrm{H}_{2} \mathrm{O}$. Once the adsorbent is saturated, the bed is vented by decreasing the pressure and introducing a small amount of pure $\mathrm{H}_{2}$ to drive out residual $\mathrm{O}_{2}$ and $\mathrm{H}_{2} \mathrm{O}$. Hydrogen recovery is less than unity because a small quantity of $\mathrm{H}_{2}$ is trapped in the adsorption bed and product gas is lost during the purge cycle. A summary of the auxiliary components needed for each system is shown in Table 2 .

A control system subassembly is also required for local and remote monitoring, alarming for hazardous conditions, and controlling of plant equipment. To minimize control costs, the lowest degree of control sophistication which allows full functionality and safe operation is assumed. Water level controllers are incorporated to assure adequate flow to the reactors, flow meters at the gas processing outlet are used to measure product flow, pressure sensors are used to monitor for pressure build-up or loss, and gas sensors are needed to sample for contaminants in the output stream. Support components such as programmable logic controllers, control room computers and software, power and instrumentation wiring, wiring conduits, alarms, and electrical power are all included in the costs. The large areas covered by the plants increase the costs of the control system and impose the need for remote control capabilities. Each reactor type requires a different number of sensors, alarms, etc. due to vastly different plant layouts. Lastly, a makeup water assembly is required to continuously feed water to the reactors as it is consumed to evolve gaseous products.

\section{Costs}

The levelized cost of hydrogen in $\$$ per $\mathrm{kg}$ for each system type was computed using the H2A model, version 2.0 in 2005 U.S. dollars. The DOE H2A analysis tool is primarily intended to compare different hydrogen production pathways or, as is the case here, different embodiments of the same approach. The 
structured format of the H2A model allows a user to enter the cash inflows and outflows associated both with construction and operation of a hydrogen production plant. A discounted cash flow analysis was performed within the H2A framework to evaluate an appropriate return on investment used to assess yearly costs for capital equipment investments. All plantspecific parameters related to location, operation, and reactor design are determined or assumed for each system design while the H2A default values for many general parameters are retained. A complete list of default values may be found in the original report ${ }^{\mathbf{1 0}}$ while an abbreviated list of the most important is shown in Table 3 along with some assumed parameters common to all systems. Note that while high purity oxygen is produced as a by-product, it is vented to atmosphere and no cost credit is taken.

This type of costing analysis is not without limitations, especially given the number of performance and cost projections required. For example, the semiconductor materials selected for pricing the functional materials in each system embodiment, such as $\mathrm{Fe}_{2} \mathrm{O}_{3}$ and $\mathrm{TiO}_{2}$, do not have the required functionality. While serving as a good starting point for a cost surrogate, serviceable materials may be considerably more expensive. It is also very difficult to engineer a single semiconductor to act both as an excellent absorber and efficient catalyst but the cost of adding a co-catalyst was not directly considered. However, one of the coated layers already incorporated in the costs could be a catalyst layer. It is important to bear in mind that there is currently no infrastructure for a hydrogen distribution network and the cost of delivery outside of the plant gate is not assessed. This analysis targeted only the production cost of the hydrogen in getting it to the plant gate at the desired purity and pressure as dictated by the H2A analysis.

Table 3 Selected H2A default and assumed input parameters for the H2A costing analysis

\begin{tabular}{|c|c|}
\hline \multicolumn{2}{|l|}{ H2A default values } \\
\hline $\begin{array}{l}\text { Operating period and } \\
\text { facility life }\end{array}$ & 20 years \\
\hline Construction period & 1 year \\
\hline $\begin{array}{l}\mathrm{CO}_{2} \text { capture credit, } \mathrm{CO}_{2} \\
\text { production taxes or } \mathrm{O}_{2} \text { credit }\end{array}$ & None \\
\hline Depreciation type & $\begin{array}{l}\text { Modified accelerated cost } \\
\text { recovery system (MACRS), } 20 \text { years }\end{array}$ \\
\hline Inflation rate & $1.9 \%$ \\
\hline Land cost & $\$ 500$ per acre \\
\hline $\begin{array}{l}\text { Hydrogen pressure at } \\
\text { central gate }\end{array}$ & 300 psig \\
\hline Hydrogen purity & $\begin{array}{l}98 \% \text { minimum; CO }<10 \mathrm{ppm}, \\
\text { sulfur }<10 \mathrm{ppm}\end{array}$ \\
\hline $\begin{array}{l}\text { Production facility } \\
\text { maintenance \& repair }\end{array}$ & $\begin{array}{l}0.5 \% \text { of direct capital cost } \\
\text { (per year) }\end{array}$ \\
\hline Burdened labor rate for staff & $\$ 50$ per hour \\
\hline Assumed common parameters & \\
\hline Operating capacity factor & $90 \%$ \\
\hline Site preparation & $\begin{array}{l}1 \% \text { of direct costs minus unique } \\
\text { excavation costs }\end{array}$ \\
\hline Engineering and design & $7 \%$ of direct costs \\
\hline Process contingency & $20 \%$ \\
\hline
\end{tabular}

The primary purpose of this work is to report the main findings of the cost analysis and as such, many of the costing details incorporated in the report issued by $\mathrm{DTI}^{\mathbf{1 0}}$ are not discussed here. We focus on identifying the major contributors to cost for each type of PEC system. Some system-specific costs are discussed below with a summary of all capital and operating costs for each system which lead to a levelized cost of hydrogen in $\mathrm{S}$ per $\mathrm{kg} \mathrm{H}_{2}$.

\subsection{System-specific costs}

The particularities of each cell and plant design result in unique costs associated with a specific system type. For the Type 1 and 2 systems, the reactor baggies cover a considerable land area. Thus, care was taken to accurately determine excavation costs based on local labor rates, equipment required, and estimated time to level the area for one baggie. The estimated excavation costs exclusively for leveling the land under the baggies were \$46 259 and \$82 237 for the Type 1 and Type 2 systems, respectively. Costing of the particles was based on a slurry coating process similar to that used in the pharmaceutical industry; the particles are modeled as $40 \mathrm{~nm} \mathrm{Fe} \mathrm{O}_{3} \mathrm{O}_{3}$ (\$188 per kg) substrates coated with two $5 \mathrm{~nm}$ layers of $\mathrm{TiO}_{2}$ ( $\$ 278$ per $\mathrm{kg}$ ). Assuming a production volume of $41600 \mathrm{~kg}$ per year (sufficient to evolve $500 \mathrm{TPD} \mathrm{H}_{2}$ ), a short Design for Manufacture and Assembly (DFMA) analysis yields a total cost of \$304 per $\mathrm{kg}$ of which $\$ 209$ per $\mathrm{kg}$ is materials, $\$ 17$ per $\mathrm{kg}$ is the coating process, and $\$ 79$ per $\mathrm{kg}$ is the markup to account for scrap, R\&D, and profit. While cheaper production technologies may be developed and the demand volume may be vastly different, it will be shown that these developments would have a minimal impact on the final $\mathrm{H}_{2}$ cost, which is fairly insensitive to particle cost due to the low mass of particles required. For the Type 3 system, the cost of panel electrodes is a key factor. Given the present lack of industrial production of such electrodes, costs are based on the solar cell open literature cost reports, NREL cost projections for solar cells, ${ }^{59}$ and a DFMA style cost analysis. A cost of \$150-\$200 per $\mathrm{m}^{2}$ is assumed based on using low cost PV printing techniques. For the Type 4 system, the processing subassembly, along with pumps and the control system, will require electrical power. Furthermore, water is required as a feedstock for electrolysis. The utility usage was computed for each system, as shown in Table 4, and the H2A model rates were used to find the total utilities cost. Plant staffing requirements were based on the assumption that one worker could oversee 100 acres of baggies or panels and a plant supervisor is required for large operations.

\subsection{System capital costs}

All components except for the HDPE baggies, photoactive particles, and PEC cells were assumed to have a 20 year lifetime and not contribute to yearly replacement costs. Both the baggies and particles were assumed to have a five year service lifetime for the Type 1 and Type 2 systems while the PEC panels for the Type 3 and Type 4 systems had an assumed lifetime of 10 years. Lifetime refers to the length of time the component is in use prior to being replaced but does not consider any deterioration 
Table 4 Utility usage for unit operations and feedstocks for 1 TPD $\mathrm{H}_{2}$ production plant modules of each of the four reactor types

\begin{tabular}{|c|c|c|c|c|}
\hline & $\begin{array}{l}\text { Type } 1 \text {, single } \\
\text { bed particle suspension }\end{array}$ & $\begin{array}{l}\text { Type } 2 \text {, dual bed } \\
\text { particle suspension }\end{array}$ & $\begin{array}{l}\text { Type } 3 \text {, fixed } \\
\text { panel array }\end{array}$ & $\begin{array}{l}\text { Type } 4 \text {, tracking } \\
\text { concentrator array }\end{array}$ \\
\hline \multicolumn{5}{|l|}{ Power consumption } \\
\hline Compressor (kW) & 128.6 & 76.3 & 76.3 & - \\
\hline Pumps (kW) & 1.1 & 0.9 & 0.7 & 0.22 \\
\hline PSA $(\mathrm{kW})$ & 1.0 & - & - & - \\
\hline Control system $(\mathrm{kW})$ & 6.5 & 6.5 & 6.5 & 6.5 \\
\hline Average power consumption (kW) & 137.2 & 83.7 & 83.5 & 6.7 \\
\hline \multicolumn{5}{|l|}{ Water consumption } \\
\hline Electrolysis (kg per day) & 9928.8 & 8935.9 & 8935.9 & 8935.9 \\
\hline Vapor loss (kg per day) & 53.1 & 31.9 & 31.9 & 31.9 \\
\hline Total usage (kg per day) & 9981.9 & 8967.8 & 8967.8 & 8967.8 \\
\hline
\end{tabular}

in performance. For all system types, the bulk of the cost of hydrogen stems from capital expenditures. The capital cost of each 1 TPD system was calculated and the results are summarized in Table 5 .

\subsection{Levelized hydrogen cost \& sensitivity analysis}

Each system was designed for 1 TPD $\mathrm{H}_{2}$ production but the overall levelized cost of hydrogen calculation assumes a 10 TPD $\mathrm{H}_{2}$ demand and thus, 10 plant modules each producing 1 TPD. The increase in scale primarily results in a decrease in labor costs per kilogram of hydrogen produced. All the systems considered are centralized hydrogen production facilities; the cost represents the price of hydrogen at the plant gate and does not take into account delivery or dispensing costs. The calculated levelized cost of hydrogen for the Type 1, Type 2, Type 3, and Type 4 systems is $\$ 1.60$ per $\mathrm{kg} \mathrm{H}_{2}, \$ 3.20$ per $\mathrm{kg} \mathrm{H}_{2}, \$ 10.40$ per $\mathrm{kg} \mathrm{H}_{2}$, and $\$ 4.10$ per $\mathrm{kg} \mathrm{H}_{2}$, respectively. There is some uncertainty in the absolute output values ( $\$$ per $\mathrm{kg} \mathrm{H}_{2}$ ) emerging from this model. However, these results show that PEC hydrogen can potentially meet the DOE cost goal of \$2.00-\$4.00 per $\mathrm{kg} \mathrm{H}_{2}$ discussed later in the text. The numbers can also be used to make instructive comparisons of system costs. It is useful to break down the cost into capital costs, fixed operation and maintenance costs, variable costs, and decommissioning

Table 5 Summary of all direct capital expenditures and installation costs for the four different 1 TPD net $\mathrm{H}_{2}$ production plant modules

\begin{tabular}{|c|c|c|c|c|c|c|c|c|}
\hline \multirow[b]{2}{*}{ Reactor subassembly } & \multicolumn{2}{|c|}{$\begin{array}{l}\text { Type } 1 \text {, single bed particle } \\
\text { suspension }\end{array}$} & \multicolumn{2}{|c|}{$\begin{array}{l}\text { Type } 2 \text {, dual bed particle } \\
\text { suspension }\end{array}$} & \multicolumn{2}{|c|}{ Type 3 , fixed panel array } & \multicolumn{2}{|c|}{$\begin{array}{l}\text { Type } 4 \text {, tracking } \\
\text { concentrator array }\end{array}$} \\
\hline & Baggies & $\$ 133077$ & Baggies & $\$ 791250$ & & & $\begin{array}{l}\text { Tracking/ } \\
\text { concentrating }\end{array}$ & $\$ 2035420$ \\
\hline & Particles & $\$ 22679$ & Particles & $\$ 40798$ & PEC cells & $\$ 8238271$ & PEC cells & \$1 072904 \\
\hline & Other & $\$ 56501$ & Other & $\$ 60886$ & Other & $\$ 105074$ & Other & $\$ 26886$ \\
\hline $\begin{array}{l}\text { Reactor subassembly } \\
\text { total }\end{array}$ & $\$ 212257$ & & $\$ 892934$ & & $\$ 8343345$ & & $\$ 3135209$ & \\
\hline \multirow{5}{*}{$\begin{array}{l}\text { Gas processing } \\
\text { subassembly }\end{array}$} & Compressor & $\$ 526302$ & & & & & & \\
\hline & Condenser & $\$ 13765$ & Compressor & $\$ 315884$ & Compressor & $\$ 759481$ & & \\
\hline & Intercoolers & $\$ 30655$ & Condenser & $\$ 10626$ & Condenser & $\$ 16607$ & Condenser & $\$ 7098$ \\
\hline & PSA & $\$ 107147$ & Intercoolers & $\$ 23334$ & Intercoolers & $\$ 36389$ & Piping & $\$ 26673$ \\
\hline & Piping & $\$ 6416$ & Piping & $\$ 6811$ & Piping & $\$ 104861$ & & \\
\hline $\begin{array}{l}\text { Gas processing } \\
\text { subassembly total }\end{array}$ & $\$ 684283$ & & $\$ 356654$ & & $\$ 917338$ & & $\$ 33771$ & \\
\hline Control system total & $\$ 173944$ & & $\$ 440826$ & & $\$ 319862$ & & $\$ 279774$ & \\
\hline Direct capital cost total & $\$ 1070485$ & & $\$ 1690414$ & & \$9 580545 & & $\$ 3448755$ & \\
\hline $\begin{array}{l}\text { Reactor cost per capture } \\
\text { area (uninstalled) }\end{array}$ & $\$ 2.21$ per $\mathrm{m}^{2}$ & & $\$ 6.55$ per $\mathrm{m}^{2}$ & & $\$ 154.95$ per $\mathrm{m}^{2}$ & & $\$ 92.41$ per $\mathrm{m}^{2}$ & \\
\hline $\begin{array}{l}\text { System Cost per capture } \\
\text { area (uninstalled) }\end{array}$ & $\$ 19.76$ per $\mathrm{m}^{2}$ & & $\$ 18.46$ per $\mathrm{m}^{2}$ & & $\$ 204.81$ per $\mathrm{m}^{2}$ & & $\$ 126.51$ per $\mathrm{m}^{2}$ & \\
\hline \multirow[t]{4}{*}{ Installation } & Excavation & $\$ 46259$ & Excavation & $\$ 124672$ & Panels/reactor & $\$ 1076962$ & Reactors & $\$ 746385$ \\
\hline & Baggies/piping & $\$ 21534$ & Baggies/piping & $\$ 291441$ & Piping & $\$ 30843$ & Piping & $\$ 10521$ \\
\hline & Gas processing & $\$ 203361$ & Gas processing & $\$ 104953$ & Gas processing & $\$ 243743$ & Gas processing & $\$ 2129$ \\
\hline & Control system & $\$ 52183$ & Control system & $\$ 132248$ & Control system & $\$ 95959$ & Control system & $\$ 83932$ \\
\hline Installation cost total & $\$ 323337$ & & $\$ 653314$ & & $\$ 1447507$ & & $\$ 842967$ & \\
\hline $\begin{array}{l}\text { Total capital cost with } \\
\text { installation }\end{array}$ & \$1 393822 & & $\$ 2343728$ & & $\$ 11028052$ & & $\$ 4291722$ & \\
\hline
\end{tabular}




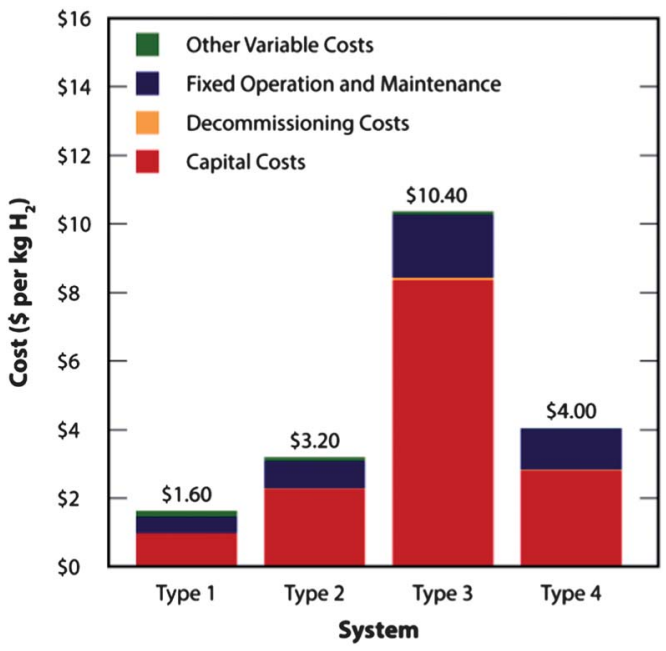

Fig. 8 Distribution of cost contributions to the levelized price of hydrogen.

costs as shown in Fig. 8. For every system, the output varies significantly over the course of the year, with the December output being much lower than the June production. If adequate storage options are not available and winter demand is high, the systems would need to be scaled up and the costs would be elevated. We once again emphasize that these are conceptual systems for which there is a large degree of uncertainty in the system performance, $\mathrm{H}_{2}$ demand schedule, durability, and cost. To help illustrate the effects of these uncertainties on the cost of the $\mathrm{H}_{2}$ output at the plant gate, a sensitivity analysis was carried out to gauge the relative effects of system efficiency and component lifetime. Sensitivity to the cost of the photocatalytic particles was also considered for the Type 1 and 2 systems while the cost of the PEC cells was considered for the Type 3 and 4 systems. The sensitivity analysis presented here is an attempt to identify the most impactful parameters on the final cost of $\mathrm{H}_{2}$ but other assumed costs (e.g. land costs, labor rates, pumps/ compressors, etc.) will also vary to some degree; a more extensive sensitivity analysis of all parameters to determine the full range of error is beyond the scope of the current work but will likely be pursued as the technology matures. The results of the sensitivity analysis are shown in Fig. 9 along with the range of evaluation parameters explored.

For all four systems, the capital costs make up a significant fraction of the overall cost. We consider the major contributions in each case to identify where design uncertainty could lead to increases in cost and where research progress could drive down costs significantly. The cost of hydrogen produced from the Type 1 and Type 2 systems is very low at $\$ 1.60$ per $\mathrm{kg}$ and $\$ 3.20$ per $\mathrm{kg}$, respectively. However, the performance of the particulate systems on a large scale is not well established given incomplete demonstration of the effective performance of particles as a function of depth in the baggies, photovoltage generated by multilayer particles, voltage losses across porous bridges, particle lifetime, and scalable particle fabrication methods. For the Type 1 system, gas compression equipment accounts for over half of the direct capital costs. Given the safety
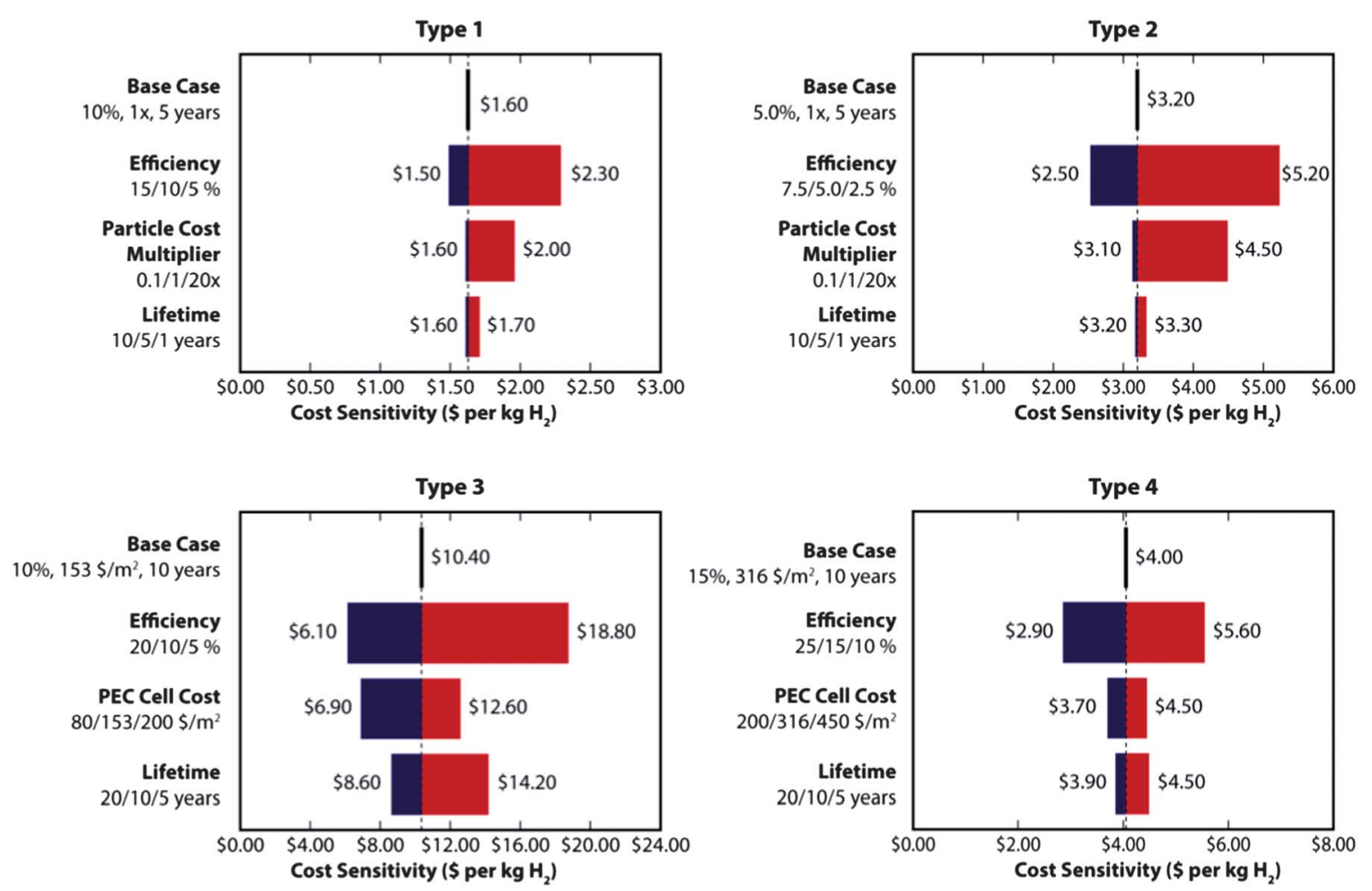

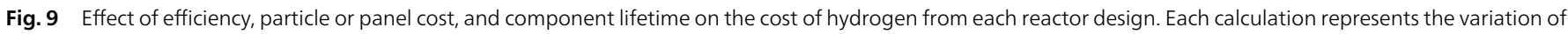
a single parameter from the base case to a higher and lower value as indicated on the left axis. 
concerns associated with compression of a combustible mixture of stoichiometric $\mathrm{H}_{2}$ and $\mathrm{O}_{2}$, costs could rise as suitable engineering controls are incorporated to mitigate the risk. Another possible source of rising costs could come from increasing the number of baggies to diminish the capacity loss in case of failure, likely bringing the cost of hydrogen closer to the Type 2 system.

Among particle efficiency, cost, and lifetime, the sensitivity analysis for the Type 1 system revealed that efficiency has the biggest impact; however, all cost differentials were small. The keys to bringing this type of system to market appear to be more related to technological feasibility and could be: (i) to develop particles that provide the photovoltage required to split water but still utilize a large portion of the solar spectrum, and (ii) to find innovative solutions for the compression of the $\mathrm{H}_{2} / \mathrm{O}_{2}$ mixture.

The Type 2 system cost breakdown is similar to the Type 1 system, with the capital costs and associated installation expenses for the greater number of baggies accounting for the higher levelized cost of $\$ 3.20$ per $\mathrm{kg} \mathrm{H}_{2}$. Electrolyte voltage losses in this system could prove problematic as the redox shuttle must travel between the separate $\mathrm{O}_{2}$ and $\mathrm{H}_{2}$ generating baggies. The baggie width has been reduced to alleviate these losses but molecular transport on the order of meters rather than centimeters, typical of research cells, has not been demonstrated. A priority for developing a Type 2 system is designing the membrane bridges and slurry circulation system to minimize voltage losses while preventing $\mathrm{O}_{2}$ and $\mathrm{H}_{2}$ diffusion. In addition to demonstrating the effective use of a redox mediator, there is still the principal challenge of developing the separate particles needed for $\mathrm{O}_{2}$ and $\mathrm{H}_{2}$ generation. An advantage of this system over its Type 1 counterpart is the potential for researchers to independently optimize the $\mathrm{O}_{2}$ and $\mathrm{H}_{2}$ generating particles, allowing for much greater flexibility in designing materials. In summary, particulate systems have lower predicted cost but significant technical risk given the state of development of both the reactor systems and the photocatalytic particles.

The baseline costs of the Type 3 and Type 4 systems are higher than that of the particulate systems but leveraging the knowledge from the PV industry increases the cost certainty for components such as the concentrating system and thin film panels. Capital costs dominate the price of $\$ 10.40$ per $\mathrm{kg} \mathrm{H}_{2}$ for a Type 3 system, the highest of the four embodiments considered. More than $80 \%$ of the cost originates in the materials, construction, and installation of the photoactive cells. Given the rigid encapsulation framework, as opposed to the flexible baggies of the Type 1 and 2 reactors, compression costs for the Type 3 reactor are also high since the auxiliary units must be sized for the peak hourly output and not the average output over the day.

While the accuracy of the cost analysis for the Type 3 and 4 systems benefitted from the pricing information available from the PV industry, it also relies on the projected development of lower cost thin film materials. It is clear from the sensitivity analysis that all parameters, i.e. efficiency, cell cost, and durability of planar electrodes, affect the costs; research and development must focus on all three aspects to ultimately produce high-efficiency, stable materials that can be manufactured cheaply from earth abundant elements.

The Type 4 system, yielding a cost of $\$ 4.10$ per $\mathrm{kg} \mathrm{H}_{2}$, is the more attractive of the two panel options based on this analysis. The reduced photoelectrode area required with 10:1 solar concentration significantly reduces the capital costs associated with panel production and brings the levelized cost of hydrogen much closer to that of the slurry systems. This fact exemplifies the utility of an upfront technoeconomic analysis for energy technologies that do not yet exist at the commercial scale. Researchers can recognize that any PEC system developed in the laboratory will likely be made more cost effective at the commercial scale if $10: 1$ solar concentration is employed, thus motivating research into the effects of increased light intensity on photoabsorber materials. In the Type 4 reactor, the solar collector structure is now the primary expense driving the price of hydrogen. Progress in the PV industry has already brought these costs down but modest improvements may still be possible when considering a system tailored for PEC water splitting. Increasing the concentration ratio to $20: 1$ would further lower the costs by an estimated $10 \%$, but there may be catalysis and bubble formation issues which limit practical implementation. Efficiency is a key parameter driving costs for this system and thus materials discovery and development should focus on high efficiency systems. A PEC cell efficiency reaching $25 \%$ would reduce the levelized cost of hydrogen to a value of $\$ 2.90$ per kg. Fig. 3 illustrates that a $22.8 \%$ STH efficiency is potentially realizable in a tandem structure even when practical losses are considered; future improvements in both catalysts and semiconductors or the use of triple junction cells should allow the small step to $25 \%$.

\subsection{Cost comparison}

It is important to establish what the target cost of hydrogen should be to compete with other liquid fuels or hydrogen production technologies. In the DOE Fuel Cell Technologies Program Multi-Year Research, Development and Demonstration Plan, the objective was set to reduce the cost of hydrogen to \$2.00-\$4.00 per gasoline gallon equivalent (gge) delivered at the pump. The basis for this target is that the cost of hydrogen should be roughly the same as that of untaxed gasoline. Based on the lower heating values, one gallon of gasoline is approximately equivalent to one kilogram of hydrogen resulting in a target cost of \$2.00-\$4.00 per $\mathrm{kg} \mathrm{H}_{2}$.

The least expensive current $\mathrm{H}_{2}$ production process is steam methane reforming, which provides hydrogen at a cost of $\$ 1.00-$ $\$ 5.00$ per $\mathrm{kg} \mathrm{H}_{2}$ (ref. 60) but of course, direct consumption of fossil fuels to produce hydrogen is not a sustainable process. The low price of natural gas, likely to persist for the foreseeable future due to the recent advent of hydraulic fracturing methods, ${ }^{61}$ means the cost of $\mathrm{H}_{2}$ is likely to be on the lower end of this range. Using the linear relationship between natural gas prices and hydrogen production cost established by Lemus and Martínez Duart, the centralized cost (i.e. not including delivery) of steam methane reforming is roughly $\$ 1.25$ per $\mathrm{kg} \mathrm{H}_{2}$ based 
on recent natural gas prices around $\$ 3.50$ per GJ. ${ }^{62}$ Large-scale electrolysis, using the industrial coal-powered electricity price of $\$ 0.05$ per $\mathrm{kW}$ per $\mathrm{h}$, has a cost of $\$ 4.09$ per $\mathrm{kg} \mathrm{H}_{2}$ computed using an H2A type analysis. ${ }^{60}$ Once again, fossil fuels appear in the chemical balance sheet unless all the grid electricity comes from renewable sources. A completely clean route to hydrogen would be connecting an electrolyzer to a PV array, both commercial technologies today which can be coupled. ${ }^{63}$ While the cost of PV is coming down, it is still not as cheap as coalpowered electricity. ${ }^{64}$ As a result, if the grid electricity supplying the electrolyzer was replaced with PV electricity, the cost would still be $>\$ 4.09$ per $\mathrm{kg} \mathrm{H}_{2}$. We emphasize that the full technoeconomics of PV-electrolysis is outside of the scope of this work but such a project would be interesting. Clearly there is room for optimization of the coupling of PV and electrolysis, such as considering load leveling, which would presumably drive costs down. A technoeconomic analysis of PV-electrolysis could serve to identify pathways to achieve the DOE goal as the analysis presented here has done for the case of direct water photolysis.

A previous report that evaluated the cost of hydrogen produced from several distributed and centralized technologies, without consideration of costs of compression, storage and delivery, revealed that the price of production alone was $\$ 1.61$ per $\mathrm{kg}$ for centralized biomass gasification, $\$ 1.33$ per $\mathrm{kg}$ for natural gas reforming, \$4.50 per $\mathrm{kg}$ for wind electrolysis, and $\$ 2.05$ per $\mathrm{kg}$ for coal gasification with carbon capture. ${ }^{65}$ These costs would be slightly higher if compression to 300 psi were included to directly compare to the PEC hydrogen production costs. Given the estimated costs for $\mathrm{H}_{2}$ at 300 psi from the four conceptual water splitting systems described in this paper, as low as $\$ 1.60$ per $\mathrm{kg} \mathrm{H}_{2}$ for particle-based systems and $\$ 4.10$ per $\mathrm{kg} \mathrm{H}_{2}$ for concentrated panel systems, it is clear that PEC hydrogen production is a viable option among the carbon-free processes. Interestingly, a previous analysis carried out nearly two decades ago, using a slightly different methodology and assumptions, came to the same conclusion that a dual bed particle-based system would be more economical than a commercial PV coupled to an electrolyzer, a multilayer panel PEC system, or a concentrated multilayer panel PEC water splitting system. ${ }^{66}$

\section{Conclusions}

The levelized cost of hydrogen was computed using standard H2A methodology to assess the viability of photoelectrochemical water splitting as a carbon-free means to produce hydrogen. The four conceptual systems evaluated were a Type 1 single bed particle suspension, a Type 2 dual bed particle suspension, a Type 3 fixed panel array, and a Type 4 tracking concentrator array. For each photoabsorber arrangement, theoretical efficiency calculations were carried out and compared to actual laboratory-scale materials benchmarks in order to determine reasonable target system efficiencies. The baseline levelized production cost of hydrogen was computed to be $\$ 1.60, \$ 3.20, \$ 10.40$, and $\$ 4.10$ per $\mathrm{kg} \mathrm{H}_{2}$ for the Type 1 , Type 2, Type 3 and Type 4 systems, respectively. The particle slurry systems have significantly lower capital costs but there is greater uncertainty associated with their operation, such as safety concerns over the cogeneration of $\mathrm{H}_{2}$ and $\mathrm{O}_{2}$ for the Type 1 system or the long molecular transport lengths of redox shuttles in the Type 2 system. The panel array systems are more expensive due to their significant capital costs. Panel fabrication and encapsulation costs dominate for the Type 3 system while the solar concentrator and tracking components drive the cost of the Type 4 system. However, the sensitivity analysis reveals that there is a significant opportunity to reduce the cost of the panel-based systems by improving materials efficiency and by employing solar concentration. PEC cell cost and durability are also secondary drivers for the cost of the output hydrogen. This work clearly demonstrates that if technical progress is made to meet material performance targets and with appropriate plant-scale engineering, direct solar hydrogen produced by photoelectrochemical water splitting can be produced at a cost which meets the DOE target of \$2.00-\$4.00 per $\mathrm{kg} \mathrm{H}_{2}$.

\section{Acknowledgements}

The authors would like to thank the U.S. Department of Energy's PEC Working Group, organized by the Office of Energy Efficiency and Renewable Energy's Fuel Cell Technologies Office, for its instrumental role in initiating and sustaining the technoeconomic analysis of the photoelectrochemical hydrogen production pathway. We also thank Steven Y. Reece, Joep J. H. Pijpers, Niels H. Damrauer, and Thomas D. Jarvi for their constructive feedback on this paper. BAP received funding from NSF grant CHE-0802907 for CCI Solar Fuels, a United Technologies Research Center fellowship in Sustainable Energy, and a Natural Sciences and Engineering Research Council of Canada graduate award. JDB received support from the National Science Foundation Graduate Research Fellowship Program and a Stanford Graduate Fellowship. LCS also received funding from the National Science Foundation Graduate Research Fellowship Program. AJF and TFJ received support from the U.S. Department of Energy, Office of Energy Efficiency and Renewable Energy through Subcontract no. NFT-9-88567-01 'and AGB2-11473-01 under Prime Contract no. DE-AC36-08-GO28308. JDB, LCS, and ZC were supported by the Center on Nanostructuring for Efficient Energy Conversion (CNEEC) at Stanford University, an Energy Frontier Research Center funded by the U.S. Department of Energy, Office of Science, Office of Basic Energy Sciences, under Award no. DE-SC0001060. TGD was supported by the U.S. Department of Energy Fuel Cell Technologies Office under Contract no. DE-AC36-08-G028303 with the National Renewable Energy Laboratory. SA received support through a DOE-EERE Postdoctoral Research Award under the EERE Fuel Cell Technologies Program.

\section{Notes and references}

1 N. Armaroli and V. Balzani, ChemSusChem, 2011, 4, 21-36.

2 Z. Wang, R. R. Roberts, G. F. Naterer and K. S. Gabriel, Int. J. Hydrogen Energy, 2012, 37, 16287-16301. 
3 A. Ursua, L. M. Gandia and P. Sanchis, Proc. IEEE, 2012, 100, 410-426.

4 S. K. Ngoh and D. Njomo, Renewable Sustainable Energy Rev., 2012, 16, 6782-6792.

5 A. Fujishima and K. Honda, Nature, 1972, 238, 37.

6 O. Khaselev and J. A. Turner, Science, 1998, 280, 425-427.

7 S. Licht, B. Wang, S. Mukerji, T. Soga, M. Umeno and H. Tributsch, J. Phys. Chem. B, 2000, 104, 8920-8924.

8 S. Y. Reece, J. A. Hamel, K. Sung, T. D. Jarvi, A. J. Esswein, J. J. H. Pijpers and D. G. Nocera, Science, 2011, 334, 645-648.

9 R. E. Rocheleau, E. L. Miller and A. Misra, Energy Fuels, 1998, 12, 3-10.

10 B. D. James, G. N. Baum, J. Perez and K. N. Baum, Technoeconomic Analysis of Photoelectrochemical (PEC) Hydrogen Production, Directed Technologies Inc., (US DOE Contract no. GS-10F-009J), Arlington, VA, 2009.

11 E. Miller, Advanced Materials for Water Photolysis, US DOE, Task 26 Annual Report, Washington, 2011.

12 M. G. Walter, E. L. Warren, J. R. McKone, S. W. Boettcher, Q. X. Mi, E. A. Santori and N. S. Lewis, Chem. Rev., 2010, 110, 6446-6473.

13 A. J. Nozik and R. Memming, J. Phys. Chem., 1996, 100, 13061-13078.

14 T. Bak, J. Nowotny, M. Rekas and C. C. Sorrell, Int. J. Hydrogen Energy, 2002, 27, 991-1022.

15 M. Kitano and M. Hara, J. Mater. Chem., 2010, 20, 627-641. 16 A. Kudo and Y. Miseki, Chem. Soc. Rev., 2009, 38, 253-278.

17 S. van Riesen, A. Gombert, E. Gerster, T. Gerstmaier, J. Jaus, F. Eltermann and A. W. Bett, AIP Conf. Proc., 2011, 1407, 235238.

18 G. S. Kinsey, K. Stone, J. Brown and V. Garboushian, Prog. Photovoltaics, 2011, 19, 794-796.

19 R. K. Jones, P. Hebert, P. Pien, R. R. King, D. Bhusari, R. Brandt, O. Al Taher, C. Fetzer, J. Ermer, A. Boca, D. Larrabee, X. Q. Liu and N. Karam, 2010 35th IEEE Photovoltaic Specialists Conference (PVSC), 2010, pp. 000189-000195.

20 P. C. K. Vesborg and T. F. Jaramillo, $R S C A d v .$, 2012, 2, 79337947.

21 Z. Chen, T. F. Jaramillo, T. G. Deutsch, A. KleimanShwarsctein, A. J. Forman, N. Gaillard, R. Garland, K. Takanabe, C. Heske, M. Sunkara, E. W. McFarland, K. Domen, E. L. Miller, J. A. Turner and H. N. Dinh, J. Mater. Res., 2010, 25, 3-16.

22 M. F. Weber and M. J. Dignam, J. Electrochem. Soc., 1984, 131, 1258-1265.

23 M. F. Weber and M. J. Dignam, Int. J. Hydrogen Energy, 1986, 11, 225-232.

24 M. C. Hanna and A. J. Nozik, J. Appl. Phys., 2006, 100, 0745101-074510-8.

25 W. Shockley and H. J. Queisser, J. Appl. Phys., 1961, 32, 510519.

26 R. T. Ross, J. Chem. Phys., 1967, 46, 4590-4593.

27 R. E. Rocheleau and E. L. Miller, Int. J. Hydrogen Energy, 1997, 22, 771-782.

28 J. R. Bolton, S. J. Strickler and J. S. Connolly, Nature, 1985, 316, 495-500.
29 S. Hu, C. Xiang, S. Haussener, A. Berger and N. S. Lewis, Energy Environ. Sci., 2013, DOI: 10.1039/c3ee40453f.

30 R. T. Ross and T. L. Hsiao, J. Appl. Phys., 1977, 48, 47834785.

31 L. C. Seitz, Z. Chen, A. J. Forman, B. A. Pinaud, J. D. Benck and T. F. Jaramillo, unpublished work.

32 S. Schuldiner, J. Electrochem. Soc., 1959, 106, 891-895.

33 Y. Gorlin and T. F. Jaramillo, J. Am. Chem. Soc., 2010, 132, 13612-13614.

34 X. B. Chen, S. H. Shen, L. J. Guo and S. S. Mao, Chem. Rev., 2010, 110, 6503-6570.

35 J. G. Mavroides, J. A. Kafalas and D. F. Kolesar, Appl. Phys. Lett., 1976, 28, 241-243.

36 A. B. Ellis, S. W. Kaiser and M. S. Wrighton, J. Phys. Chem., 1976, 80, 1325-1328.

37 N. Kobayashi, T. Narumi and R. Morita, Jpn. J. Appl. Phys., Part 2, 2005, 44, L784-L786.

38 I. Waki, D. Cohen, R. Lal, U. Mishra, S. P. DenBaars and S. Nakamura, Appl. Phys. Lett., 2007, 91, 093519-1-093519-3. 39 A. J. Nozik, Appl. Phys. Lett., 1976, 29, 150-153.

40 R. C. Kainthla, B. Zelenay and J. O. Bockris, J. Electrochem. Soc., 1987, 134, 841-845.

41 J. H. Park and A. J. Bard, Electrochem. Solid-State Lett., 2006, 9, E5-E8.

42 H. Arakawa, C. Shiraishi, M. Tatemoto, H. Kishida, D. Usui, A. Suma, A. Takamisawa and T. Yamaguchi, Proceedings of the SPIE - The International Society for Optical Engineering, 2007, vol. 6650, p. 665003.

43 J. Brillet, M. Cornuz, F. Le Formal, J. H. Yum, M. Gratzel and K. Sivula, J. Mater. Res., 2010, 25, 17-24.

44 J. Brillet, J. H. Yum, M. Cornuz, T. Hisatomi, R. Solarska, J. Augustynski, M. Graetzel and K. Sivula, Nat. Photonics, 2012, 6, 823-827.

45 E. L. Miller, B. Marsen, D. Paluselli and R. Rocheleau, Electrochem. Solid-State Lett., 2005, 8, A247-A249.

46 A. Madan, Photoelectrochemical hydrogen production, http:// www.hydrogen.energy.gov/pdfs/review11/pd053_madan_ 2011_o.pdf, accessed 29 November 2012.

47 S. Licht, B. Wang, S. Mukerji, T. Soga, M. Umeno and H. Tributsch, Int. J. Hydrogen Energy, 2001, 26, 653659.

48 O. Khaselev, A. Bansal and J. A. Turner, Int. J. Hydrogen Energy, 2001, 26, 127-132.

49 G. Peharz, F. Dimroth and U. Wittstadt, Int. J. Hydrogen Energy, 2007, 32, 3248-3252.

50 A. Kudo, H. Kato and I. Tsuji, Chem. Lett., 2004, 33, 15341539.

51 K. Maeda, K. Teramura, L. Daling, T. Takata, N. Saito, Y. Inoue and K. Domen, Nature, 2006, 440, 295.

52 R. Abe, K. Sayama and H. Sugihara, J. Phys. Chem. B, 2005, 109, 16052-16061.

53 K. Fujihara, T. Ohno and M. Matsumura, J. Chem. Soc., Faraday Trans., 1998, 94, 3705-3709.

54 C. A. Linkous, N. Z. Muradov and S. N. Ramser, Int. J. Hydrogen Energy, 1995, 20, 701-709.

55 A. Mills and S. Le Hunte, J. Photochem. Photobiol., A, 1997, 108, 1-35. 
56 D. M. Blake and C. Kennedy, Hydrogen reactor development and design for photofermentation and photolytic processes, Report CH-560-38480, NREL, Golden, CO, 2005.

57 A. Luque, J. Appl. Phys., 2011, 110, 031301-1-031301-19.

58 S. Haussener, C. X. Xiang, J. M. Spurgeon, S. Ardo, N. S. Lewis and A. Z. Weber, Energy Environ. Sci., 2012, 5, 9922-9935.

59 K. Zweibel, Sol. Energy Mater. Sol. Cells, 2000, 63, 375-386.

60 B. Kroposki, J. Levene, K. Harrison, P. K. Sen and F. Novachek, Electrolysis: Information and Opportunities for Electric Power Utilities, Report NREL/TP-581-40605, NREL, Golden, CO, 2006.

61 J. J. Conti, P. D. Holtberg, J. A. Beamon, A. M. Schaal, J. C. Ayoub and J. T. Turnure, Annual Energy Outlook 2011, Report DOE/EIA-0383 (2011), Washington, DC, 2011.
62 R. G. Lemus and J. M. Martínez Duart, Int. J. Hydrogen Energy, 2010, 35, 3929-3936.

63 N. A. Kelly, T. L. Gibson and D. B. Ouwerkerk, Int. J. Hydrogen Energy, 2011, 36, 15803-15825.

64 D. Feldman, G. Barbose, R. Margolis, R. Wiser, N. Darghouth and A. Goodrich, Photovoltaic (PV) Pricing Trends: Historical, Recent, and Near-Term Projections, Report DOE/GO-1020123839, Golden, CO, 2012.

65 M. Ruth, M. Laffen and T. A. Timbario, Hydrogen pathways: Cost, well-to-wheels energy use, and emissions for the current technology status of seven hydrogen production, delivery and distribution scenarios, Report TP-6A1-46612, NREL, Golden, CO, 2009.

66 D. L. Block, in Proceedings of the 12th World Hydrogen Energy Conference, Buenos Aires, Argentina, 1998, vol. 1, pp. 185-194. 